\title{
Necessity-Rich, Leisure-Poor: The Long-Term Relationship Between Income Cohorts and Consumption Through Age-Period-Cohort Analysis
}

\author{
Esa Karonen ${ }^{1}\left[\right.$ ] Mikko Niemelä ${ }^{1}$
}

Accepted: 28 June 2021 / Published online: 17 July 2021

(c) The Author(s) 2021

\begin{abstract}
The main aim of this study is to analyse household consumption patterns in the highest and lowest income quintiles and explore how they have changed over time and generations. Thus, the article explores whether social inclusivity through consumption has truly increased. This study utilises the cross-sectional time-series data of the Finnish Household Expenditure Surveys (HESs), covering the period 1966-2016. We use the Age-Period-Cohort Gap/Oaxaca (APCGO) model with logitrank dependent variables as the main statistical method. Our results indicate that an overall high income is advantageous with respect to income and spending, though the gap between high- and low-income groups has remained stagnant over cohorts. A more in-depth analysis reveals that the expenditure gap, in terms of necessities, food, and groceries consumption, has narrowed. Instead, income elastic-oriented spending on culture and leisure time has significantly increased in the highincome group, where the expenditure gap has expanded 60 percentage points over the cohorts. Simply put, expenditures on necessities have become more inclusive, but low-income groups are increasingly more 'leisure-poor'. Overall, high-income classes are spending an increasing amount of money on culture and leisure time over cohorts.
\end{abstract}

Keywords Age-period-cohort modelling $\cdot$ Cohort analysis $\cdot$ Consumption $\cdot$ Expenditure distribution $\cdot$ Income groups

Inclusive growth has become the central point of many current poverty reduction policies, including the Europe 2020 strategy. The main objective of inclusive growth is built on the premise that growth, before poverty reduction or a focus on post-growth redistribution, is not an optimal and sustainable poverty reduction strategy. The central idea is to create an economic environment that is built on economic inclusivity for all people (Ranieri \& Ramos, 2013). As income inequality has increased in the OECD area (OECD, 2011), researchers have asked whether this has also led to inequality of consumption (Krueger \& Perri, 2006; Slesnick, 2001). As inclusive growth and social inclusion policy work hand in hand to focus on low-income groups' growth as participatory growth, the main area of interest is the equal access to services and goods across income groups, in terms of both necessities and income-elastic goods. To map out the

Esa Karonen

eokaro@utu.fi

1 Faculty of Social Sciences, Sociology, University of Turku, 20014 Turku, Finland main outcome of these policies, we analyse the economic resources of high- and low-income groups.

The use of current income in studies of inequality is open to the obvious criticism that current income might not reflect the longer-term level of resources available to a household or individual. Temporarily high or low incomes can exaggerate the real position of the household when borrowing or saving is allowed to smooth the stream of consumption. Thus, household expenditures are clearly a better measurement of a household's well-being than pure absolute income: expenditure inequality tells us more about the longer-term differences in people's living standards, whereas measures of income merely provide us with a snapshot of income differences across the population (Blundell \& Preston, 1995, 1998; Friedman, 1957; Slesnick, 2001). Several studies have argued that consumption inequality has risen less than income inequality (Cutler et al., 1991; Fisher et al., 2013; Heathcote et al., 2010; Krueger \& Perri, 2006; Meyer \& Sullivan, 2013), whereas others have argued that the rise has been fairly similar (Aguiar \& Bils, 2015; O. Attanasio et al., 2014; Bils \& Aguiar, 2010; Fisher et al., 2015). 
However, the development of expenditure inequality at the aggregate level cannot reveal the intricacies of expenditure dynamics in terms of inter-cohort inequalities. This situation would benefit from a life course perspective that identifies and controls the effects of age, time, and generation. In this study, we define life course as life events, transitions, and trajectories with cohort variation in expenditure development (Elder, 1997), as developmental patterns that are structured by events and other biological and social constraints and that vary by historical time. An individual is defined as being a part of a certain historical period or an event by his/her birth year. The impact of a historical event is contingent on the point of intersection in the life stage of the cohort (Elder, 1997). Such a perspective emphasises that expenditure changes can be associated with such dimensions as a generation's cultural context, periodic economic shocks, and age-related needs.

Existing studies on expenditures and the social stratification of consumption are mostly concerned with period changes or age group differences and have rarely measured cohort differences (e.g., Aguiar \& Bils, 2015; Erlandsen \& Nymoen, 2008; Meyer \& Sullivan, 2013). The main shortcoming of previous research on expenditure inequality is that studies have usually employed narrower models that only consider age and period variables of the age-periodcohort (APC) combination, eliminating the possibility of estimating true cohort effects (Attanasio et al., 2014; Bils \& Aguiar, 2010; Fernandez-Villaverde \& Krueger, 2002; Heslop, 1987; Rindfleisch, 1994; Twigg \& Majima, 2014). In addition, because of methodological limitations, it was not possible, until recently, to use APC analysis to estimate between-group differences, which has prevented more elaborate consumption analysis. What makes our contribution vital is our use of a new method of age-period-cohort modelling, the Age-Period-Cohort Gap/Oaxaca (APCGO) model, which is capable of measuring the absolute gap between two groups; standard APC models can only produce estimates for one sample group, which denies the possibility for between-group comparison (Bar-Haim et al., 2019; Chauvel $\&$ Schroder, 2014; Chen et al., 2001; Freedman, 2017; Karonen \& Niemelä, 2020). With the improved model, created for between-group comparison, we can expand the understanding of expenditure differences between high- and lowincome groups.

The budget constraints of income groups differ, and it is general knowledge that the extremes of income groups tend to consume a different mix and amount of products (Deaton, 1992; Deaton \& Muellbauer, 1980). Here, we assert that the improvement in the between-groups gap is associated with a change of household's social inclusion on markets as a result of increased participation possibilities. Therefore, the relationship and gap between lower and higher deciles becomes more evident as we measure expenditures on such necessities as food and such income-elastic goods as cultural and leisure-time activities. The gap itself reveals more if economic growth has yielded either more inclusive or more exclusive outcomes. Thus, we measure high- and lowincome groups' income distribution fluctuations or consumer behaviour changes in expenditure profiles. By considering the primary needs and more luxury-oriented expenditures of households, we can determine how inclusive a society is in terms of its different socioeconomic groups.

This article measures the relationship of low- and highincome cohorts in Finland through consumption and income, utilising a highly advanced ACP framework. This article contributes to the body of consumption studies by answering two primary research questions. First, the article investigates how inter-cohort income and spending profiles in high- and low-income deciles have changed over the years 1966-2016. Second, it examines to what extent inter-cohort consumption profiles between high- and low-income households differ in specific categories of consumption.

\section{Theoretical Framework and Previous Studies}

\section{Theory of Consumer Research and Consumption}

One of the main lines of consumer research is focused on consumption potential, which analyses the ability of a household to maintain a certain standard of living (Spilerman, 2000). Slesnick (1991, 1993) has stated that, ideally, we should characterise and construct the concept of economic well-being in terms of consumption expenditures and the consumption of different commodities. Consumerbased measures can produce different results in terms of the level and direction of inequality (Johnson \& Shipp, 1997; Slesnick, 1991). The theoretical literature that emphasises the importance of consumption in the stratification process argues that consumption is not only a means of acquiring necessities or daily needs but also a mechanism that organises social structures (Douglas \& Isherwood, 1996; Slater, 1999). Thus, consumption habits and patterns reproduce elements of social stratification through the structural location of households. The concept of consumption frames a multifaceted phenomenon that creates new hierarchies by which people are measured, resources are distributed and competed for, and inequalities are created (Katz-Gerro $\&$ Talmud, 2005). Therefore, the complexity of the link between consumption and inequality should be explored through the complex relationship between consumption patterns and other social domains, which are well-known links to stratification, including the stratification of different income groups.

The major elements of household stratification are linked to the relative position of a household by the dimensions 
of time, age, and date of birth. Cohorts, or generations, are shaped and defined by their particular age-related involvement with prominent historical events during the lifetime of the members of the cohort (Howe \& Strauss, 1992). Cohorts carry a unique imprint-which includes such traits as consumption habits and preferences - that is acquired through shared socialisation, caused in part by growing up in similar historical circumstances (Mannheim, 1928). In addition to cohort effects, age effects are variations resulting from the biological and social processes of aging that are specific to individuals, such as physiological changes and the accumulation of social experience (Reither et al., 2009). We can assume that as person grows older, their wealth accumulates over time. This accumulated wealth could grant various consumption options that are not necessarily available to younger people due their resource constraints, such as lower income and wealth. Period effects are defined as external variations across time periods that simultaneously influence all age groups (Yang \& Land, 2014). Period effects encompass a wide range of historical and social factors: examples of such factors include the occurrence of an economic crisis or changes in income and relative prices (Dutt \& Padmanabhan, 2011; Mckenzie et al., 2011; Räsänen, 2003; Reither et al., 2009; Zurawicki \& Braidot, 2005). Hence, time-sensitive events, such as cultural shifts (Rindfleisch, 1994), can play an enormous role in how a given generation adopts different consumption habits in relation to the resources available. For these reasons, we utilise an APC model to untangle these three dimensions, as they all play a role in household consumption preferences.

Consumption patterns reflect dimensions of APC effects and inequality in two ways. First, economic resources like income, occupation, and access to wealth or loans stratify consumption options. Second, consumer culture promotes hierarchies of taste that are constantly being created and changing (Douglas \& Isherwood, 1996; Katz-Gerro \& Talmud, 2005). These hierarchies both reconstitute and challenge social cleavages based on gender, occupation, class, age, or education. Several variables are strongly associated with expenditure patterns: income (Bihagen, 1999; Blundell \& Preston, 1995; Cohen, 2016; Heslop, 1987; Katz-Gerro, 2003; Katz-Gerro \& Talmud, 2005; Koelln et al., 1995; Salcedo \& Izquierdo Llanes, 2020); factors related to household composition such as number of adults, their ages, and number of children (Bihagen, 1999; Deutsch et al., 2015; Fernandez-Villaverde \& Krueger, 2002; Koelln et al., 1995; Raper et al., 2002; Toivonen, 1992; Uusitalo, 1980); and class and occupation (Bihagen, 1999; Cohen, 2016; Tomlinson, 1994; Uusitalo, 1980; Wittmayer et al., 1994). Although household consumption behaviour correlates strongly with income, it, alone, is an unsatisfactory predictor of consumption style differences as measured by budget allocation (Blundell \& Preston, 1998; Uusitalo, 1980). In addition to the way that socio-demographic variables are linked to expenditure patterns, research also indicates the significance of identification with group preference and the lack of commercial opportunities (Fan \& Lewis, 1999; Semyonov \& LewinEpstein, 2013; Semyonov et al., 1996).

To conclude, this paper contributes to the research field by investigating whether consumption opportunities have increased over time for the low-income group in comparison to its high-income counterpart. Thus, we trace the long-term changes in expenditures and consumption goods of low- and high-income groups to determine whether societal participation through consumption has become equal.

\section{Previous Studies}

Previous research has formally tested the life cycle hypothesis of consumption patterns. Sociologists have reached the consensus that consumption profiles change during a life cycle and that acquiring a certain consumer good is more desirable at certain times than at others, depending on the consumer culture and the consumer market (Felson, 1976; Hirsch, 2005; Nicosia \& Mayer, 1976). Studies have indeed shown how consumption preferences change during life course events (Gourinchas \& Parker, 2002; Kolsrud et al., 2017), such as during health changes and parenthood (Stöver, 2012). For example, Lührmann (2006) has found that households without children spend less on clothing and food than those with children but invest excess resources in leisure time and dining out. Thus, at these life stages, people change their needs and wants in accordance with the constraints of their household budgets. In addition, research shows that the life cycle model holds, as the sensitivity of consumption growth to labour income disappears when demographic (such as age) and business cycle (such as period) factors are controlled. This indicates a need for an APC analysis (Attanasio \& Browning, 1993) because periodic and cohort changes must also be taken into account.

Previous empirical sociological studies have usually focused on single countries and have explored levels and structures of consumption and relevant trends (Blow et al., 2004; Bögenhold \& Fachinger, 2000; Gardes \& Starzec, 2004; Herpin \& Verger, 2000; Langlois, 2001, 2002, 2003; Noll \& Weick, 2005; Schettkat \& Deelen, 2004). Overall, evidence on consumption has shown that households diversify their spending as their income and wealth increase; hence, resource optimising behaviour tendencies are thought to drive this process (Deutsch et al., 2015; Krueger \& Perri, 2006; Räsänen, 2003). In low-income groups, households have relatively concentrated spending patterns, but they tend to diversify as their income increases (Fernández-Villaverde \& Krueger, 2002; Krueger \& Perri, 2006; Räsänen, 2003). In addition, the level of heterogeneity in expenditure diversity grows along 
with income (Chai et al., 2015). An interesting question is whether institutional change in consumption has affected the expenditure patterns of these groups.

Overall, it seems that, over time, expenditure has increased in real terms but become more unequal, as people are now spending much more of their money on income-elastic goods than on necessities (Blow et al., 2004). One of the few true APC consumption studies, conducted by Segall (2013), analysed household basic expenditure categories, including food and nondurable goods. The results indicated that the expenditure share of nondurable goods, such as leisure-time goods, had an especially high share of consumption, while necessities such as food had a decreasing share of the expenditure budget. In a more in-depth study conducted during an economic crisis, consumers smoothed their expenditures across categories of consumer goods when faced with crisis event (Dutt \& Padmanabhan, 2011). Moreover, the smoothing process during a crisis differs from a corresponding change in income and prices (Mckenzie et al., 2011). Middle-class consumers seem to spend more time shopping, even though total consumption expenditures decline in real terms, because consumers seek out lower prices and spend more time locating substitutes (Dutt \& Padmanabhan, 2011; Zurawicki \& Braidot, 2005). In addition, consumer behaviour changes during economic fluctuations can be observed from a cohort perspective (e.g., Chet et al., 2001; Kerr et al., 2003; Sagell, 2013). For example, Urbonavičius and Pikturnienè (2010) analysed consumer response to an economic crisis based on the behaviour of two generations of Lithuanian consumers; their findings indicate that the younger generation tried to maintain its consumption level, while the older generation aimed to cut consumption expenditures. The reason for the difference in economic behaviour was accounted to older generation's ability to demonstrate more consistent and rational purchase behaviour in relation to income than the younger generation. Thus, it is essential to track different income groups' expenditures and determine whether we observe changes in terms of expenditure on necessities and income-elastic goods.

In summary, social change is defined as a continuous process of institutional adjustment and transformation, during which a community experiences constantly changing circumstances that modify the structural foundations of the community (Hirsch, 2005). From a practical perspective, these institutional adjustments include measures to public income transfers and services that aim to secure the living standards of the needy and by doing so also to ensure the balance in society (Hirsch, 2005; OECD, 2011). In such circumstances, inclusivity aims to advance equitable opportunities for all economic participants during economic growth to increase benefits for all income groups (Ranieri \& Ramos, 2013).

\section{Research Design}

When choosing the appropriate metric for the three dimensions of time in APC analysis, consumption is clearly a better measure of a household's well-being than absolute income: expenditure inequality tells us more about the longterm differences in people's living standards, whereas measures of income provide us with only a snapshot of income differences across the population, and further, temporarily high or low incomes may exaggerate the real position of a household when borrowing or saving is allowed to smooth the stream of consumption (Blundell \& Preston, 1995, 1998; Friedman, 1957; Uusitalo, 1980; Zaidi \& de Vos, 2001). In addition, it is imperative to compare different socio-demographic groups, like high- and low-income groups, as their budgetary limitations and needs are linked to expenditure patterns; such comparison is necessary for the identification of these groups' preferences or lack of economic opportunities (Fan \& Lewis, 1999; Semyonov et al., 1996).

We base our measurement scale of high- and low-income quintiles on Fig. 1, which shows clear descriptive differences between these two groups. The high-income group has a similar profile to the money income and money spending trajectory of the population as a whole, in which money income is higher than money spending. On the other hand, the lowincome group has a polarised money income and money spending profile, in which income is lower than the spending trajectory. This indicates that the low-income group is struggling more to make ends meet: this has major implications for the societal participation of this group. For example, low-income group could be in a persistent preference loop for precautionary saving over discretionary consumption, which limits the opportunity to do activities outside of making ends meet, such as self-development. A one-fifth measure is a moderate sample of income distribution. From a social inclusion perspective, this also makes sense: optimising the distribution of economic resources provides greater population access to a variety of products and services that would otherwise not be accessible. Spending on goods can serve as a proxy for societal participation through consumption, whereas comparing high- and low-income households offers a window onto how social inclusivity and economic opportunities have developed over time. We denote our first hypothesis on the overall development of income and spending as follows: the relative money expenditure gap between high-income and low-income groups has widened in favour of the high-income group $(\mathrm{H1})$.

The consumption gap between high- and low-income groups is time sensitive, as needs and the supply of 
Fig. 1 Logarithm of income and expenditures by income class in Finland, 1966-2016. Vertical lines represent economic recessions

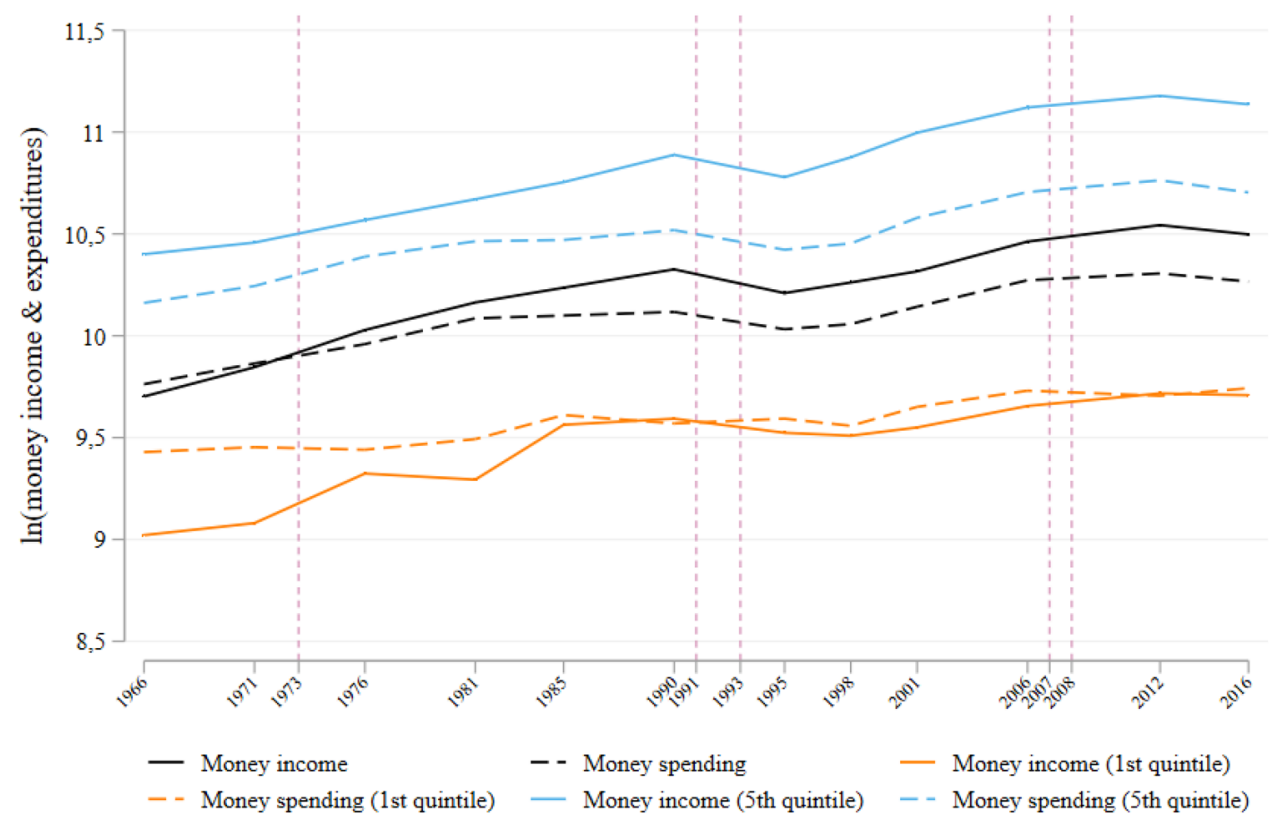

income-elastic goods changes over time. We might imagine that if people today are richer than they were a hundred years ago, they might demand different goods and different quantities of those goods. In particular, they might come to cultivate tastes for high-quality or luxury goods, especially in the high-income group. As average Finnish incomes have risen over the past century, we can anticipate that households' optimal allocation of expenditures will shift towards more income-elastic luxury goods. Treating consumption patterns as one dimension along which this generational logic can operate allows us to test whether different cohorts actually spend differently and whether those differences coincide with our prior understandings of economic history, social inclusion, and the placement of a household in the institutional network of the time.

Cohort differences in expenditures on necessities indicate whether increased income can be allocated to other expenditures. As Engel's law states, the increase in a necessity good is less than proportional to the rise in income; so, the proportion of expenditure on such goods falls as income rises (Lewbel, 1999). The more necessary a good is, the lower is the price elasticity of demand, as people will attempt to buy the good regardless of the price. Consumption of food serves as one of the proxies of necessity goods. Based on these considerations, we hypothesise that relative consumption of food and groceries between high-income and low-income groups has achieved spending equality over time (H2). In other words, we assume that the food consumption 'gap' has been equalised over time because real income has risen considerably and the share of food has diminished in overall expenditures.
As mentioned above, as a household's income increases, the percentage of income spent on food decreases, whereas the proportion spent on other goods, such as luxury goods, increases. In other words, if the expenditure rise includes all income groups, it can also serve as an inclusive public good, especially for income-elastic goods. Opportunities to engage with cultural and societal interest solidify a household's inclusion in society through participation rather than by merely making ends meet. Our last hypothesis is the following: relative spending on culture and leisure time between high-income and low-income groups has risen favour of the high-income group (H3). If the null hypothesis is true, this would indicate that society has succeeded in achieving an inclusive policy or even surpassed this by decreasing the gap between low- and high-income groups.

\section{Data and Variables}

Our empirical analyses are based on the Finnish Household Expenditure Surveys (HESs) conducted by Statistics Finland. This dataset belongs to the series the Official Statistics of Finland (OSF) and the European Statistical System (ESS). The HESs provide data on households' annual use of money for a variety of purposes, such as food or transport. There is also a wealth of information on households' structures, activities, durable goods, housing conditions, income, and social services benefits.

From 1966 to 1990 , the survey was conducted regularly at five-year intervals. From 1994 to 1996, the survey was conducted annually. Thereafter, the Household Expenditure 
Surveys were conducted in 1998, 2001, 2006, 2012, and 2016. We use all the measurement waves (1966 to 2016) in this study. Data are partially derived from interviews and, since the 1971 survey, from official registers. The household budget survey data are collected via interviews, diaries, and purchase receipts kept by the households and from administrative registers. The body of data is collected via interviews that inquire about a household's background data, its ownership and purchase of durable goods, residential costs, and several other kinds of information. After the main interview, the households keep a diary about their consumption expenditures and retain receipts from their purchases for a fortnight. Demographic as well as income data are derived from registers.

The basic unit of analysis is the household. Households most often form economic relationships through co-residence, pooling of resources, and shared consumption behaviour. Households are a social unit and a consumption unit: major economic decisions are shared and formed in relation to household status. Thus, most of the daily decisions are made within a larger unit rather than by an individual
(Katz-Gerro \& Talmud, 2005). Economic behaviour is constrained by available resources, which limits how household units can operate as a consumption unit. Regarding household assets, the individual with the highest personal income was chosen as the reference person who would serve as a proxy for the household's demographic and background status. The income variables measure the household's income and the individual income of the household's reference person. Consumption expenditure is classified according to the national Classification of Individual Consumption by Purpose Adapted to the Needs of Household Budget Surveys.

Dependent variables are inflation adjusted currency in euros, and money income, money spending, food and grocery expenditures, and cultural and leisure-time expenditures are equivalised (see Table 1 for descriptives). In dataset of HES statistical years 1966-1985 income variables use older Finnish national currency, Markka (FIM). Finland changed their currency during the 2002 monetary transition, where the Finnish markka was converted to euro with a standard coefficient of 5,94,573. We transformed old currency FIM to EUR with this transformation to harmonise the income
Table 1 Descriptive statistics, statistical years 1966-2016

\begin{tabular}{lrr}
\hline & Mean & Std. Dev \\
\hline Dependent variables & & \\
Money income (EUR) & $33,368.74$ & $21,737.83$ \\
Logarithmic money income & 10.23 & 0.64 \\
Money spending (EUR) & $29,034.43$ & $18,284.44$ \\
Logarithmic money spending & 10.09 & 0.63 \\
Food and grocery expenditures (EUR) & 3748.88 & 1936.65 \\
Logarithmic food and grocery expenditures & 8.10 & 0.57 \\
Culture and leisure-time expenditures (EUR) & 1297.49 & 2128.81 \\
Logarithmic culture and leisure-time expenditures & 6.53 & 1.73 \\
Independent variables & & \\
Education & & 0.50 \\
Basic education & 0.45 & 0.46 \\
Secondary education & 0.30 & 0.43 \\
Higher education & 0.25 & 0.46 \\
Main type of economic activity & & 0.23 \\
Worker & 0.22 & 0.46 \\
Higher and lower salariats & 0.08 & 0.28 \\
Entrepreneurs & 0.36 & 0.44 \\
Agriculture & 0.10 & 0.48 \\
Not working or outside the workforce & 0.23 \\
Structure of the household & & 0.38 \\
Single parent households & 0.02 & 0.27 \\
Couples with children & 0.36 & \\
Couples without children & 0.08 & \\
Single households & & \\
Other households & & \\
N: 78,038 & & \\
\hline & & \\
\hline
\end{tabular}

Dependent variables equivalised and inflation adjusted; Population weight added 
variable. We use aggregate food and grocery expenditures, which are constructed from 282 separate food item variables that include details on every aspect of food items from specific types of meat to different types of cabbage. Culture and leisure time are also used as aggregates and contain the total expenditures of 133 variables. For example, cultural subcategories include details about items as varied as hockey sticks and theatre tickets. It is to be noted that household income is not top-coded (no upper limit on recorded data) and is a representative sample of the Finnish population. In addition, as is common practice in empirical applications, we have bottom-coded all negative income values as zeroes because it makes little sense to apply equivalisation to negative values (see OECD, 2013, 2015).

For the independent variables, we use education, main type of economic activity, and household structure (Table 2). Education can be seen as a resource that provides one with culture, credentials, and identity, all of which are connected to cultural status, the attainment of a certain income level, and lifestyle choices. The main type of economic activity also reflects spending habits and possible out-of-work status, both of which define overall resource allocation. The variable is constructed from the Statistics Finland's Classification of Socio-economic Groups. It consists of the employees, which are classified according to socio-economic groups into upper-level and lower-level employees and manual workers. Self-employed persons can be grouped into selfemployed without employees, self-employed with employees and unpaid family workers. The household structure is used as a control to account for the different consumption needs and preferences of singles as compared to, for example, couples with children. It is to be noted that we did not include income as independent variable, as it is highly collinear with quintile group variables and would be in conflict with model assumptions. As income is an important factor in consumption, we decided to do separate analysis for income gaps between high- and low-income groups.

We coded education as basic education, secondary education, and higher education. The reference group for the main type of economic activity is workers; the other categories are higher- and lower-salary workers, entrepreneurs, agricultural workers, and individuals who are unemployed or outside the workforce. The main economic activity classification is based on the Statistics Finland's classification standard of socio-economic groups. Overall on classifications, workers are regarded as blue-collar workers (manufacturing etc.), whereas higher- and lower salariats are white collar workers (management and administration etc.). The household structure is treated as a categorical variable; the most typical households are standalone categories, and rarer ones (such as families with over five children) are combined into one category. In addition, our methodological choice comes with certain requirements regarding data structure and coding, which is described in the methodology section below.

\section{Methodology}

\section{Age-Period-Cohort Model}

We use a special variation of the APC model, which is designed to measure differences between two distinct groups (for a discussion of this methodology, see Yang et al., 2004). This variation is a major improvement over previous models; which allows us to measure only one group at a time (see e.g. Chauvel \& Schroder, 2014; Chen et al., 2001; Freedman, 2017; Reither et al., 2009). Between-group analyses are made possible through an analytical design built on interactions, even though methodological reasons prevent a comparison of results for age, period, or cohort.

The purpose of the APCGO model is to measure the change between two groups (e.g. high- and low-income groups) across birth cohorts in the gap in a dependent variable $y$ (e.g. income and expenditures) (Bar-Haim et al., 2018). Data fitted to the APCGO model are structured in a Lexis table. In our dataset, we use an age by period table (e.g. cross-sectional) of data with matching grouping intervals between age and period variables (e.g. a five-year age grouping). Each cell of the Lexis table is indexed by its age $A$ and a period $P$, as these pertain to cohorts, yielding $C=P-A$. Through the APCGO model, we identify a vector of 'net' income quintile gaps (measured by the classical Oaxaca 'unexplained difference' of $y$ by relevant covariates), where the gaps are indexed by cohorts. This cohort indexed gap is a vector showing the intensity of the gap (the average value of the vector coefficients), the trend (the general linear slope of coefficients across cohorts), and their fluctuations (their nonlinear shape); it measures a possible closing gap from social generation to generation.

The process is twofold. First, with the base of the BlinderOaxaca $r$ models of $\gamma$ by relevant control variables in each (age by period) cell of the initial Lexis table $y_{a p c}$, we compute a matrix $u_{a p c}$ of 'unexplained' differences and the 'Oaxaca-Lexis table' of income and expenditure gaps between the

Table 2 Example of logit(rank) units (Chauvel \& Bar-Haim, 2017)

\begin{tabular}{llllllllll}
\hline Logit(rank) & -4 & -3 & -2 & -1 & 0 & 1 & 2 & 3 & 4 \\
\hline Position in distribution & Low 2\% & low quintile & Low decile & Low quartile & p50 & Top quartile & Top decile & Top quintile & Top 2\% \\
\hline
\end{tabular}


highest and lowest deciles. Second, the Oaxaca-Lexis table is decomposed on the basis of a specific trended APC model to obtain a measure of the cohort-specific nonexplained gap in income (Bar-Haim et al., 2018).

In the first step, we apply the Blinder-Oaxaca decomposition method (Blinder, 1973; Jann, 2008; Oaxaca, 1973; Oaxaca \& Ransom, 1994) to each cell of the initial Lexis table to obtain the income quintile gaps in household expenditures (HSE) (un)explained by independent variables. We consider incomes for the first $\left(Q U_{1}\right)$ and fifth quintiles $\left(Q U_{5}\right)$, a linear combination of endowments and sum of errors.

$\overline{\log (H S E)}_{c}^{Q U 1}=\bar{X}_{c}^{Q U 1} b_{c}^{Q U 1}+e_{1}$

$\overline{\log (H S E)}{ }_{c}^{Q U 5}=\bar{X}_{c}^{Q U 5} b_{c}^{Q U 5}+e_{2}$

In Eq. 1, the $\bar{X}_{c}^{Q U 1}$ represents the mean of independent variable $\mathrm{X}$ at cohort $\mathrm{C}$ for the first quintile; likewise, $\mathrm{b}$ in $b_{c}^{Q U 1}$ represents the coefficient for the same independent variable and quintile cohort groups. Similarly, in the second equation, the same definitions apply except for the fifth quintile. When we subtract Eqs. 1 and 2, we express the differences in expenditures to income quintiles for each cohort:

$$
\begin{aligned}
& \overline{\log (H S E)}_{c}^{Q U 1}-\overline{\log (H S E)}_{c}^{Q U 5} \\
& \quad=b_{c}^{Q U 1}\left(\bar{X}_{c}^{Q U 1}-\bar{X}_{c}^{Q U 5}\right)+\bar{X}_{c}^{Q U 5}\left(b_{c}^{Q U 1}-b_{c}^{Q U 5}\right)
\end{aligned}
$$

In Eq. 3, the subtraction of HSE terms is the overall expenditure gap in cohort $\mathrm{C}$ between income groups, and $b_{c}^{Q U 1}\left(\bar{X}_{c}^{Q U 1}-\bar{X}_{c}^{Q U 5}\right)$ is the gap explained by independent variable $\mathrm{X}$ in a cohort $\mathrm{C}$. The term $\bar{X}_{c}^{Q U 5}\left(b_{c}^{Q U 1}-b_{c}^{Q U 5}\right)$ is the unexplained variation, which contains the effect not observed in the model.

In the twofold decomposition, the mean outcome difference is the difference in the linear prediction at the groupspecific means of the regressors of the difference, which can, in the case of the two groups, be decomposed. We apply a specific trended APC model to the Oaxaca Lexis table to obtain the trend measure of the cohort-specific expenditure gap, the APCT-lag coefficient. The new APC-lag approach uses the 'linear age effect' as its baseline (Bar-Haim et al., 2017; Bar-Haim et al., 2018). Once this constraint is given and the period linear trend is constrained to zero, the cohort effect will absorb the long-term time transformations. This definition means a new, clear baseline, at which the linear slope of age trend measured by the $\alpha_{a}$ coefficients is designed to equal $\alpha$, the average shift due to age in the Oaxaca Lexis table across cohorts $O_{a p c}$. Consider this average shift $\alpha$ :

$\alpha=\sum \frac{\left(O(\alpha+1, p+1, c)-O_{a p c}\right)}{(A-1)(P-1)}$ where $\alpha$ represents the average shift for a cohort $\mathrm{c}$ when it grows one age group older in the next period across the window of observation of a age groups and $\mathrm{p}$ periods. Once $\alpha$ is known, APC-lag is identifiable:

$o^{a p c}=\alpha_{a}+\pi_{p}+\gamma_{c}+\varepsilon$

whereas the full model is denoted as

$\left\{\begin{array}{c}o^{a p c}=\alpha_{a}+\pi_{p}+\gamma_{c}+\beta_{0}+\sum_{j} \beta_{j} x_{j}+\varepsilon_{i} \\ \left\{\begin{array}{c}\sum\left(\alpha_{a}\right)=0 ; \sum\left(\pi_{p}\right)=0 \\ \operatorname{Trend}\left(\pi_{p}\right)=0 ; \operatorname{Trend}\left(\alpha_{a}\right)=\alpha\end{array}\right.\end{array}\right.$

The formula of operator trend for age coefficients, when A is the number of age coefficients, is

$\operatorname{Trend}\left(\alpha_{a}\right)=12 \frac{\sum\left(\alpha_{a}(2 a-A-1)\right)}{(A-1) A(A+1)}$

In the APC-lag, $\gamma_{c}$ absorbs the constant (larger when the gap is high), its trend shows the variation in the intensity of the gap by cohort for age and period controlled, and the fluctuations show possible nonlinear accelerations or decelerations in the cohort trend.

It should be noted that the complete APCGO method cannot provide direct estimations of confidence intervals due to the complexity of the succession of the Blinder-Oaxaca and APC methods. Therefore, we bootstrap the entire process considered, including the Blinder-Oaxaca decomposition of each cell of the initial Lexis table of $y_{a p c}$ to obtain the nonexplained $O_{a p c}$ Oaxaca-Lexis table. For a more comprehensive methodological discussion, see the relevant research literature (Chauvel \& Bar-Haim 2017; Chauvel et al., 2017). Estimation results are shown in appendix in Tables 3 and 4.

\section{Transformation of the Dependent Variables}

For the outcome variable (expenditures) we utilise the percentile rank-based elasticity measure, or 'logitrank' method, on our dependent variables (Chauvel, 2016; Chauvel \& BarHaim, 2017). Logitrank offers a standardisation method consistent with the Pareto characteristics of income and consumption distributions that suppresses the mechanical effect of increasing gaps with increasing inequalities. One of these effects is yearly variation, which rank ordering income will control. Thus, we can explain the gap in the means of our outcome variables between the first and fifth quintiles and measure the relative social power of individual i (Copas, 1999). Logitrank can be expressed as the following equation:

$\ln \left(m_{j}\right)=\alpha \ln \left(\frac{p_{1}}{1-p_{i}}\right)$ or $M_{i}=\alpha X_{i}$ 
where $X_{i}=\operatorname{logit}\left(p_{i}\right)=\ln \left(p_{i} /\left(1-p_{i}\right)\right)$ and $M_{i}=\ln (\mathrm{mi})=\ln \left(y_{i}\right.$ (median).

There are two types of strong arguments that support the use of a logitrank as a first approximation of income distributions (Chauvel \& Bar-Haim, 2017). In technical terms, first, with its two-parameter formula (the median and $\alpha$ ), the logitrank is one of the most parsimonious laws with appropriate Pareto-type power tails at both extremes, and its formula is simple. In this model, log medianised income is proportional to the log-odds of the standardised quantile (Table 2). Thus, the coefficient plays a remarkable role in the measurement of inequality since rank positions offer an opportunity to measure changes in wage and consumption structures. Second, the logitrank has some important features, such as power tails and the ability to use zero wages. This is an important feature and substantial improvement over previous studies (see discussion Marx et al., 2013), as the focus on hourly wages can omit certain observations, for example, in female and unemployed populations. In addition, the main benefit is that logitrank measures are counted as infinite and not constrained as percentiles are, where a large increase in the top percentiles only moves the percentile ratio by a minimal amount, thus hindering variation in extreme groups. The logitrank solves this.

One downside of logitrank is the added complexity of interpreting results. To counteract this-as a final modification-we obtain percentiles from the logitrank estimates by using the inverse function for more intuitive results. Thus, we report the results of analysis both in units of logitrank and percentiles. The inverse function with the median centred to zero is denoted as follows:

Percentile Rank $(P R)=\frac{\operatorname{EXP}(\text { Logitrank })}{(1+\operatorname{EXP}(\text { Logitrank }))}-0.5$

\section{Results}

\section{Money Income and Money Spending: The Income Quintile Gap}

Figure 2 shows the results of trended cohort effects on income and spending, where zero denotes quintile equality and negative values denote low-income (lowest 20\%) advantage. All positive values refer to high-income (highest 20\%) advantage. Thus, the APCGO model reveals how money income and money spending have developed across cohort classes. The first part of our analysis focuses on income quintile differences in logitranked money income and money spending with and without control variables.
Results indicate that the long-term money income development has favoured the highest decile. In money income, there is a 48-percentage point gap between the high- and low-income groups. It seems that there has not been any real development in income inequality between the high- and low-income groups over cohorts. Thus, the results suggest that money income growth has equally benefitted highand low-income quintiles. Any deviation would show an increased gap, which would also indicate growth or decline in income inequality. From the viewpoint of social inclusivity, this development is optimal, in the sense that income development has been a Pareto improvement, although the income gap has not decreased between income deciles over cohorts. Even taking education into account, the main economic activity and the structure of households, there are no real changes in the overall income gap. It should be noted that previous research shows that there was an increase in income inequality in Finland during the 1990s recession, but the effect was mostly due to changes in the taxation system that followed the rise in capital income (Blomgren et al., 2014). The overall resources, as in disposable money assets, have maintained their equality over cohorts.

Money expenditure shows a similar development. Overall, the expenditure gap between high- and low-income cohorts is 39 percentage points. It seems that the expenditure gap has also maintained its equilibrium over cohorts, although compared to money income, the gap varies approximately 5 percentage unit range. Although this variation is low, the trend of the gap itself has not changed between income groups between cohorts. Overall, it can be stated that high- and low-income groups have equal expenditure profiles, which also points to inclusive consumption opportunities. There is a small deviation: an expenditure spike (10 percentage points) in the cohort from 1985 to 1989. The most likely explanation for this is the volatility of this cohort group because of a lack of cases. A broader extrapolation would be that the financial crisis of 2007-2008 had an impact on this cohort group because it was entering the job market. In Finland, the financial crisis stagnated economic growth, which probably affected the recruitment policies of institutions and companies. Nevertheless, the results show that spending profiles are homogenous over cohorts between high- and low-income groups. This result does not support our first hypothesis of an increased spending gap in favour of the high-income group.

The income and spending gaps offer an overall picture of social inclusion and of how people have been spending and earning over cohorts. Our results show that both overall money income and money expenditures show equal development over cohorts. Thus, the gap in distributive balance in terms of resources and market inclusivity does seem to provide equal footing in the consumption market when budget constraints are taken into account. Nevertheless, this type of analysis does 


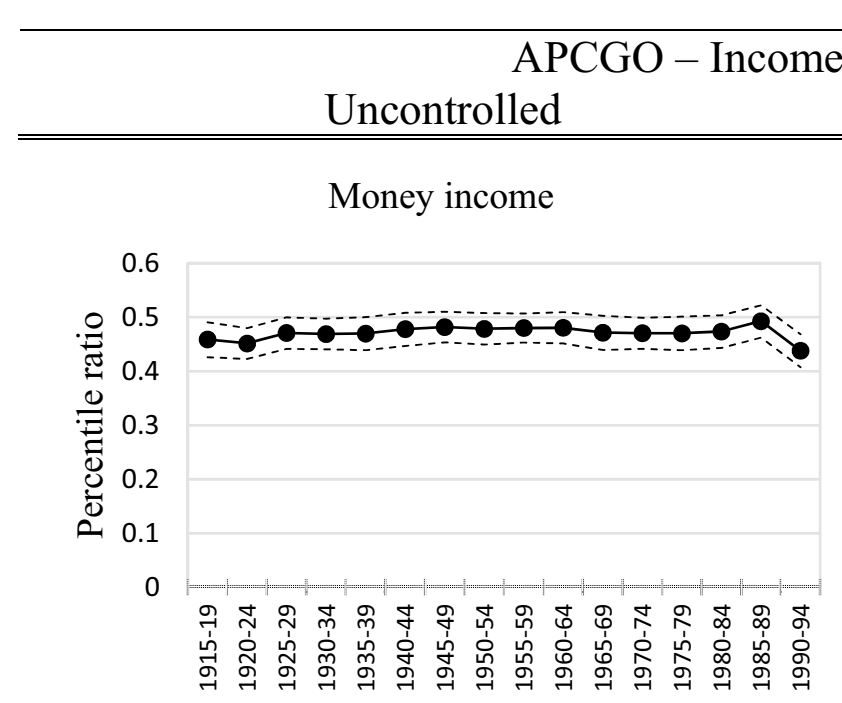

Money expenditures

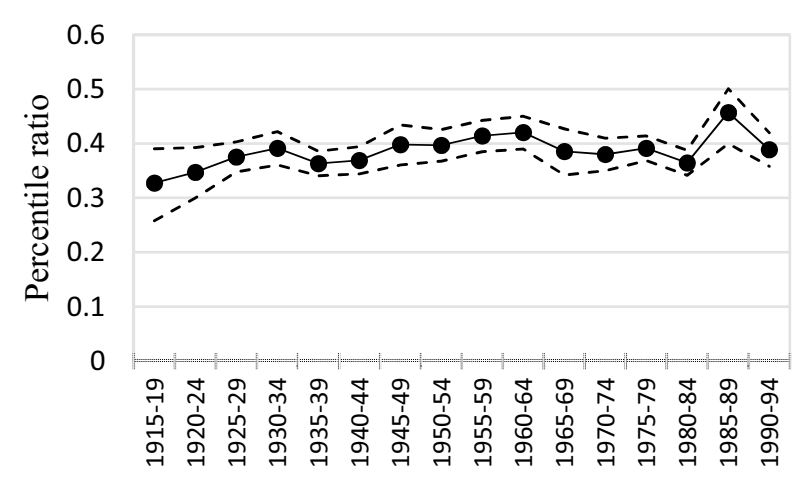

Controlled
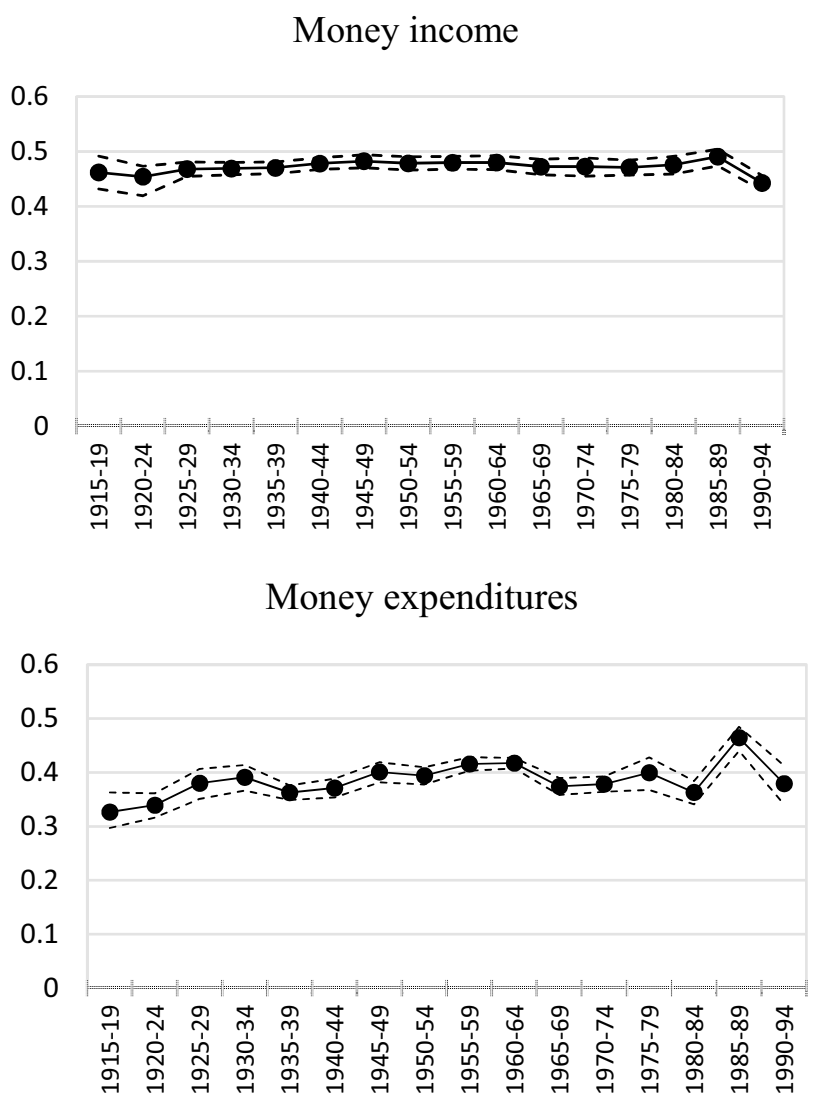

Fig. 2 Income quintile gap in percentile ratio of money income and money spending by birth cohort. Zero denotes quintile equality, and positive values refer to high-income advantage

not show how more concrete budgetary investments have been changing between people who are more affluent and people who are on a tighter budget: for example, how the consumption of food and more luxury-oriented goods has changed over different generations, thus appropriately testing the hypotheses regarding Engel's shift to income-elastic goods. This would show the inner structure of expenditures and whether inclusivity profiles have changed and become more unequal between the quintiles in older and younger generations. Next, we analyse how these two expenditure gaps have been fluctuating to provide a more in-depth view of where spending is directed.

\section{Consumption Gap in Expenditures Between Income Quintiles}

Figure 3 shows the results of the APCGO expenditure gap between the highest and lowest income quintiles. As in the previous analysis of money income and money spending, the zero line denotes quintile equality, and negative values indicate higher low-income expenditures.

Figure 3 shows how the expenditure gap in food and groceries has decreased by 17 percentage points from the oldest to the youngest cohort and how it is closing in on the expenditure equality of high- and low-income groups. Nevertheless, an 18-percentage point gap between these groups remains. There are two probable explanations for this. First, this could be interpreted as an effect of Engel curves, which states that as income rises, the proportion of income spent on food falls (Lewbel, 1999). A general increasing income trajectory is shown in Fig. 1, which, in combination with food and grocery expenditures, supports the indication of an Engel curve. Second, it is probable that the high-income group does not spend more on food in terms of volume but in terms of quality. Unfortunately, our data do not indicate how much food is purchased in grams or whether the food is of a higher quality. Nevertheless, this is a reasonable extrapolation. 


\section{Uncontrolled Controlled}

Food and grocery expenditures

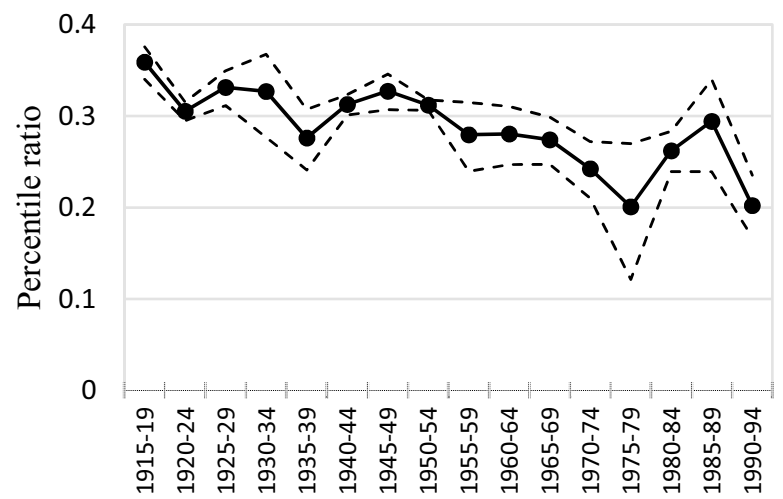

Restaurant and dining expenditures

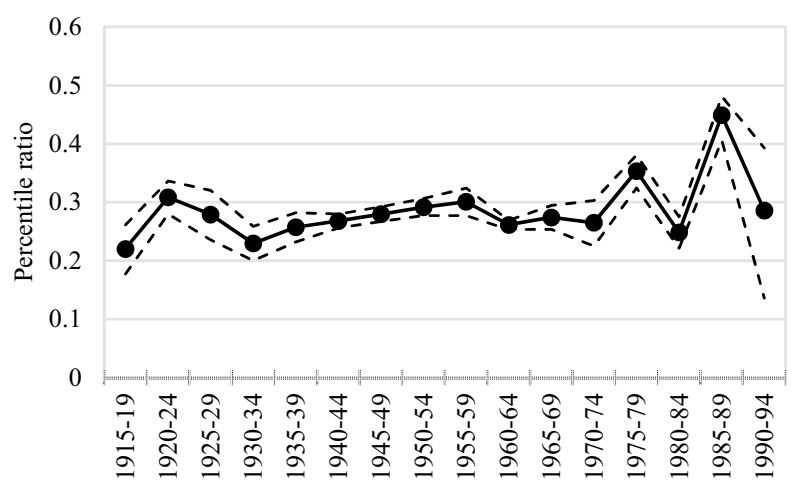

Food and grocery expenditures

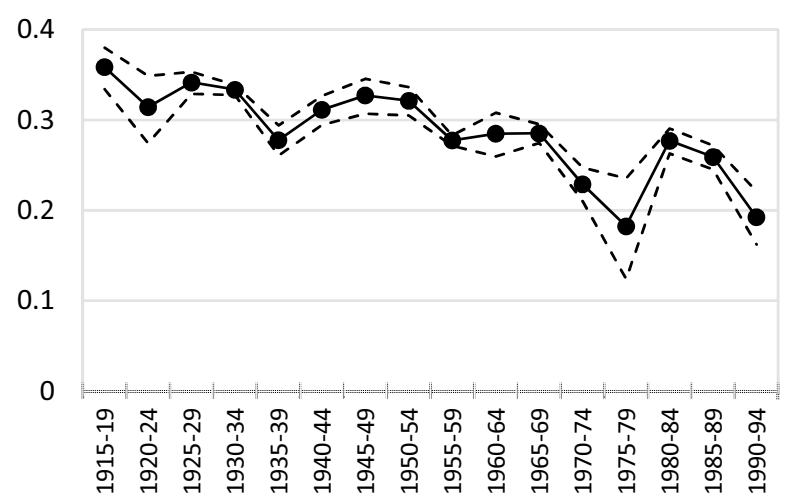

Fig. 3 Income quintile gap in percentile ratio of food and grocery expenditures and restaurant and dining expenditures by birth cohort. Zero denotes quintile equality, and positive values refer to a high-income advantage

One outlier remains between the cohorts from 1980 to 1989, which shows an increased expenditure gap in highincome households. To explain this phenomenon, we also analysed restaurant and dining expenditures, which could partly explain certain developments in food expenditures, especially in the case of cohorts. The rationale behind this notion is that cohorts could differ from each other in terms of dining culture and access to a much larger selection of dining facilities than previous cohorts. Eating out in Finland is more related to weekday activities, work and something you do with colleagues. Finland promoted the provision of cooked lunches by government institutions and private companies for decades, which could mean that the government policies may have influenced cultural preferences, and especially younger generation where these systems are more prevalent (Holm et al., 2012). As Fig. 3 shows, the restaurant and dining expenditures have been relatively stagnant with a high-income group bias (30 percentage points), but in the younger generations there is an increase in dining expenditures. This could partly explain the food and grocery expenditure increase in younger cohorts.

Although a small expenditure gap remains, the results support our second hypothesis on food and grocery consumption, which assumes that there has been a spending shift from high-income group inequality towards spending equality.

The cultural and leisure-time spending gap has risen significantly over cohorts (Fig. 4). Between the oldest and youngest cohorts, the total increase in the expenditure gap is 43 percentage points. In addition, the difference between generations shows an increased demand for culture and leisure time, especially for the affluent younger generations, who tend to spend more on leisure time. This observation supports our third hypothesis on the high-income group's increased incentive 


\section{APCGO - Cultural and leisure-time expenditures \\ Uncontrolled Controlled}
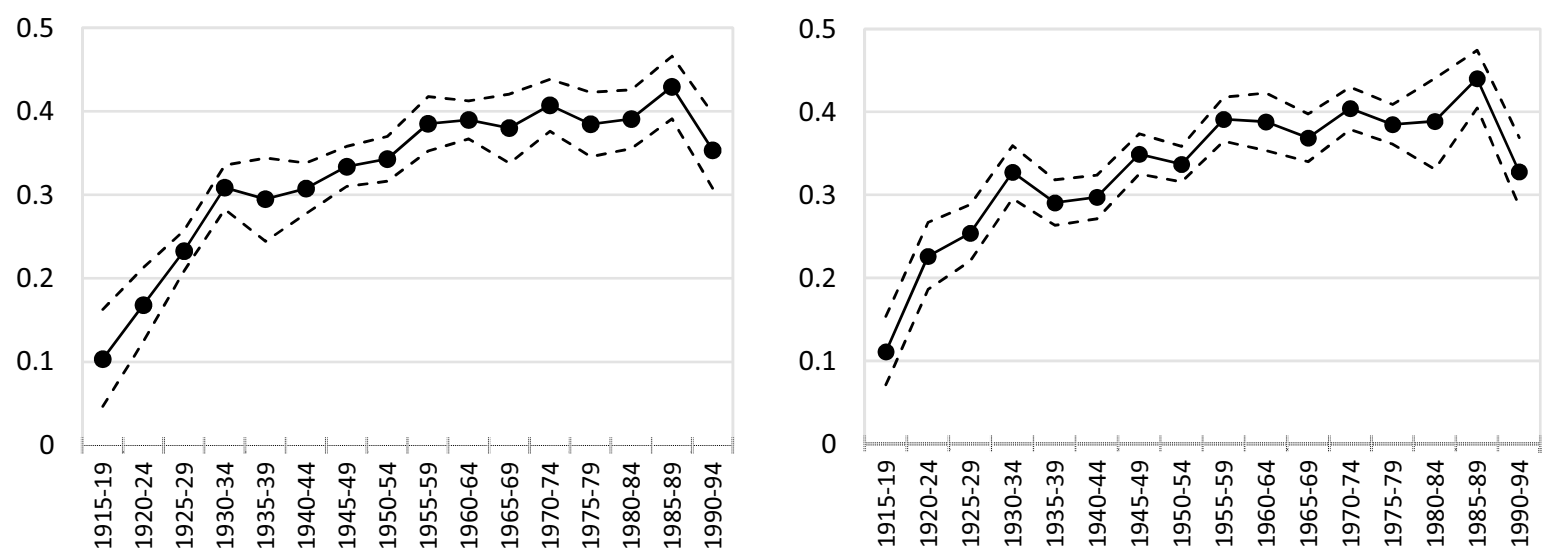

Fig. 4 Expenditure quintile gap in percentile ratio of cultural and leisure-time expenditures by birth cohort. Zero denotes quintile equality, and positive values refer to high-income advantage

to spend resources on income-elastic goods. As Engel curves dictate, the direct interpretation is that high-income groups have a greater excess of resources to spend on income-elastic goods such as culture and leisure time (Lewbel, 1999). It is reasonable to assume that there has been a major rise in an interest in culture and leisure time between cohorts in highearning households, which could be connected to class-based cultural taste (see discussion Bihagen \& Katz-Gerro, 2000; Katz-Gerro, 2002; Katz-Gerro \& Shavit, 1998). In addition, the historical contexts in which different cohorts live could play a role as could the ever-expanding supply of entertainment and leisure-time activities (Katz-Gerro, 2002).

In addition to excess resources, it is intuitively reasonable to assume that high- and low-income groups have different amounts of free time, which is where spending on culture happens. In contrast to such lay conceptions, previous studies have implied that high-wage earners and educated individuals work more hours than low-wage earners (Kuhn \& Lozano, 2008), whereas our results show increased leisure-time investment by the group with less free time. Thus, investment in culture and leisure time is not connected to free time itself but to availability of resources. As regards the expenditure gap in food and grocery expenditures, it is interesting to note that the decreased investment in necessities does not reflect leisure-time consumption. This is probably connected to other expenditures, such as housing expenditures and the preference for consuming other goods.

From the viewpoint of social inclusion, the results show that the monetary investments in culture and leisure time by the high-income group has increased over cohorts. Thus, participation in income-elastic markets has decreased in the low-income group. Put simply, low-income groups are not only more consumption-poor but also leisure-poor than their high-earner counterparts.

Next, we observe the difference between the mean differences across income quintiles with a set of control variables. By observing total differences (sum of the explained and the unexplained) in comparison to the unexplained wage gap, we can see how much these gaps persist in the general versus the explained control variable effects. This reveals how much of the gap is due to factors other than the variables that are part of the model. In other words, we gain knowledge about which factors explain why the quintile gap exists.

\section{Total Gap Blinder-Oaxaca Decomposition of the Income Quintile Gap}

The overall control variables (Fig. 5) explain the income and expenditure gaps well. The decompositions reveal that all control variables over different cohorts explain 60 percent of the total gap between high- and low-income groups. Regarding food and grocery expenditures, it seems that the control variables explain slightly less of these for the younger generations, although the difference is 10 percentage points. In conclusion, the income and expenditure gap is explained mostly by differences in education, main economic activity, and household structure. The unexplained gap could include structural factors, such as rural or urban household location and the ages of any children. In addition, psychological consumer behaviours, such as personal taste and the effects of advertisements, could interact with consumer behaviour, but these data cannot measure such (see e.g., Becker \& Murphy, 


\section{APCGO - Total quintile gap}

Money income and money spending

Money income

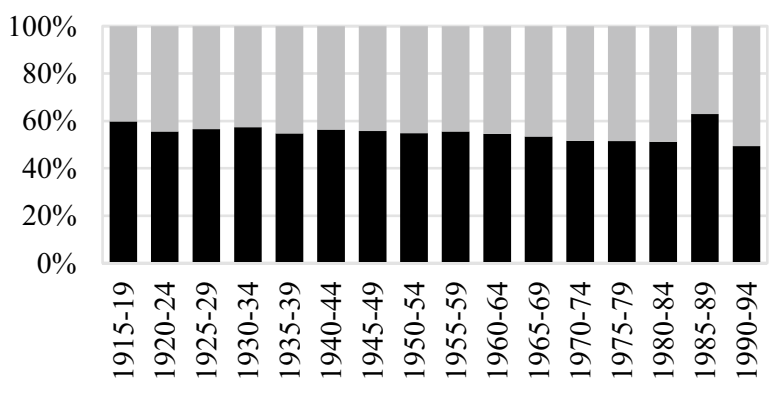

Money spending

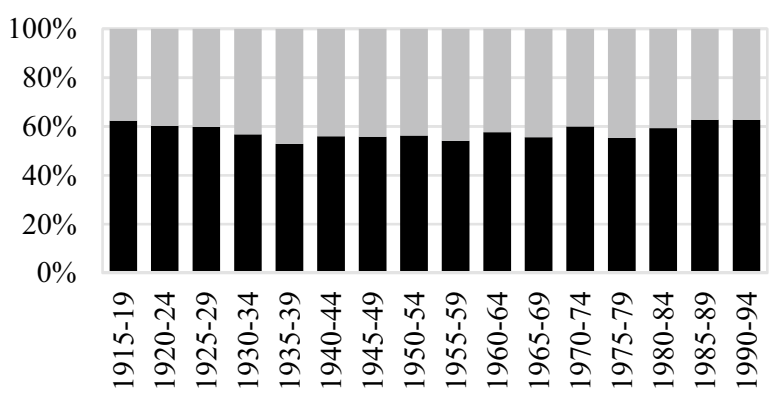

Fig. 5 Percentage share of the explained and unexplained income quintile gap controlled by education, main economic activity, and the structure of the household. Darker grey denotes the total quintile gap

2009; Blundell, 1988; Haugtvedt et al., 1992; van Raaij, 2016).

\section{Conclusion}

Our study aimed to analyse the inclusive nature of long-term economic participation by measuring the level of consumption between high- and low-income groups. By separating necessities (primary utility goods) and income-elastic goods (secondary utility goods), we found that the glass of economic inclusivity is half empty and half full.

The overall change between high- and low-income economic groups seems not to have changed at the aggregate level, which comprises the 'the glass is half full' thesis. First, our data suggest that at the aggregate level, consumption and income have maintained a stagnant gap between both extremes of the income groups. This supports the idea that overall household expenditures follow the trend of household income. In our first hypothesis we asserted that the relative money expenditures between
Food and culture consumption

Food and grocery expenditures

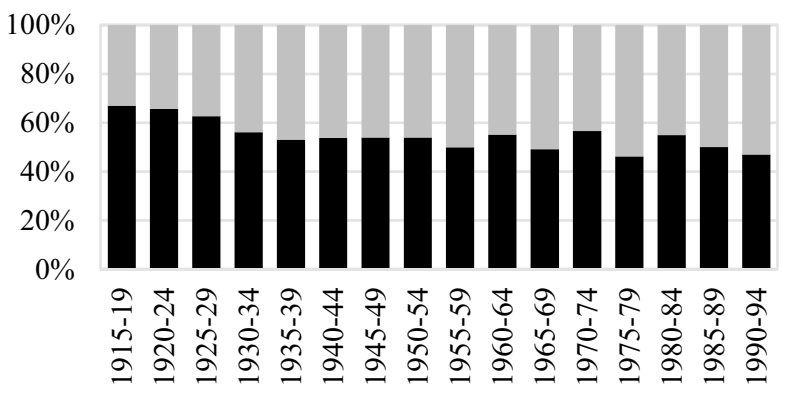

Cultural and leisure-time expenditures

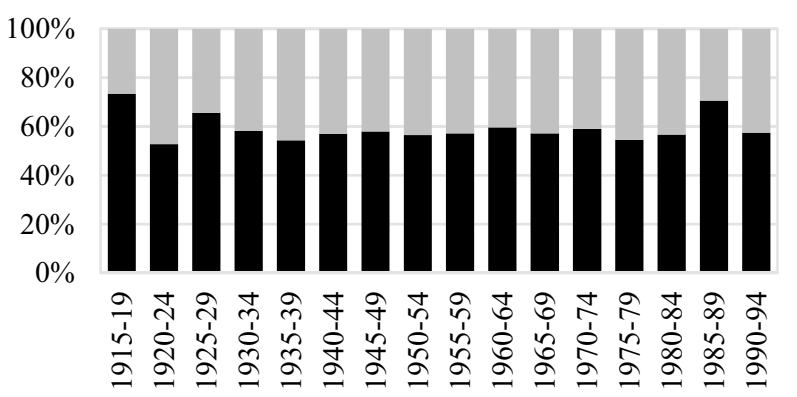

and lighter grey the unexplained quintile gap. The difference shows how much the control variables account for the gap

high-income and low-income groups have risen in favour of the high-income group. Our results falsify this hypothesis, as expenditure gap has remained stagnant. The results clearly show that the expenditure gap and income gap between highand low-income cohorts have maintained their overall stagnant nature, which indicates that the income and expenditure development has maintained its inclusive balance in aggregate measures. Finland has a strong redistributive income transfer system, especially when compared to other systems like the United States (see e.g., Autor et al., 2005; Dew-Becker \& Gordon, 2005; Goldin \& Katz, 2007). Thus, the redistributive income transfer system through progressive taxation and cash transfers through social insurance and social benefits could be one factor that partly mellows differences between these two groups (see also Fellman et al., 1999; Jäntti et al., 2020). The stagnant gap could tell us that this redistributive system has been working as intended for a long period of time, and at the surface level, it seems that long-term economic opportunities have been balanced for both high- and low-income groups and that growth trends are at similar levels. 
Second, in contrast to aggregate income and expenditures, a more in-depth analysis reveals an inequality between the two income groups. Our data support the idea of increased consumption inequality compared to income but at a more intricate level. While aggregate income and consumption have been stagnant over different cohorts, the investment in necessities (food and groceries) and income-elastic goods (culture and leisure time) shows changes in consumption inequality.

The second hypothesis, which derived its premise from Engel curves and which we denoted as relative consumption of food and groceries between high-income and low-income groups, indicates more equal spending profiles over time (Lewbel, 1999). The cohort profiles support this hypothesis, and show a decrease in the spending gap between high- and low-income groups on necessities. The results show Engel's law (Lewbel, 1999) in action and indicate that long-term increases in income have equalised people's expenditures on necessities, regardless of their socioeconomic position. The results show that inclusivity has risen in terms of necessities: food and grocery expenditures have improved over cohorts, which indicates that investment in necessities has improved in terms of inclusivity over time. One drawback of this analysis is the lack of data on the remaining gap, which could be explained by the quality of the food between highand low-income groups.

Our third hypothesis was that relative spending on culture and leisure time between high-income and low-income groups has risen in favour of the high-income group, which our results confirm. In other words, this is the "the glass is half empty' side of inclusivity. The inclusivity gap is seen in cultural and leisure-time expenditures, which serve as a proxy for income-elastic consumption. The results show that consumption inequality has risen significantly between high- and low-income groups in terms of leisure time. This indicates that the high-income group has more resources available for consumption and that high-income groups tend to use surplus resources for more income-elastic goods, such as culture and leisure time. When taking into account the long-term stagnant aggregate income and expenditure gaps between high- and low-income groups, the focus shifts to the internal structure of expenditures. It seems that an abundance of resources provides more freedom to invest in leisure time, while the low-income group remains 'leisurepoor'. It could be stated that there is a divide in inclusion in terms of culture, which creates an institutional divide between cultural classes. In conclusion, from a social inclusion standpoint, Finnish society seems to be equal in terms of access to necessary resources, but the leisure options seem to divide the high- and low-income earners. As a new insight into previous research, this could be interpreted as consumption inequality being in effect even if overall consumption and income trends maintain their uniform levels (Aguiar \& Bils, 2015; O. Attanasio et al., 2014; Bils \&
Aguiar, 2010; Bihagen \& Katz-Gerro, 2000; Fisher et al., 2015; Katz-Gerro, 2002).

While overall trends in consumer behaviour do follow previous results, such as the gap between overall income and expenditures, we observe several new findings compared to the extant body of work on this topic. Compared to Segall's (2013) APC study, we can separate income groups, and we found that expenditures on leisure time goods have increased but in favour of households with better economic resources. Thus, we can state that, indeed, households from older to younger cohorts invest more in leisure time but increasingly only those that are economically prosperous. This finding indicates, as previous research suggests (Fan \& Lewis, 1999; Semyonov et al., 1996), that there is an imbalance of consumption opportunities between different socio-demographic groups. In other words, while income has risen overall, resource spending does not follow a similar trend between high- and low-income groups; this is a contribution to previous APC studies because it disentangles interest groups. In addition, unlike previous studies in United States and OECD area (Dutt \& Padmanbhan, 2011; Mckenzie et al., 2011; Urbonavičius \& Pikturniené, 2010), our study does not find an association between economic crises and the expenditures of high- and low-income cohorts in Finland, as both income and consumption gap trends remain unaffected. Further research is needed to answer why households have a preference on maintaining their consumption level during economic crises.

The findings of the study, and its limitations, hold critical implications for future research. First, while the aim of the current study was to compare differences in food and grocery expenditures and cultural and leisure expenditures, future research should examine more closely the differences in housing expenditures from the APC perspective. While there are factors such as changes in the housing markets, migration and urbanization that can be considered as period factors, age is clearly associated with tenure type as well as with housing expenditures. Finally, due to the fact that the tenure type as well as the amount of mortgage are associated with age, we could predict that housing expenditures vary between cohorts. Only future research will answer this question conclusively. Second, one limitation of our study is the lack of data on consumption preferences, as it would be illuminating if the consumption inequality is due to difference in the budget constraint (income) or the preference for the goods. Now, our argumentation is made from the perspective of budget constraint, as those are our measuring units available. Taking account preferences would make a marvellous study for the future, if appropriate data could be found.

\section{Appendix}

See Tables 3 and 4. 
Table 3 APCGO estimates without control variables

\begin{tabular}{|c|c|c|c|c|c|c|c|c|}
\hline & \multicolumn{2}{|c|}{ Money income } & \multicolumn{2}{|c|}{ Money expenditures } & \multicolumn{2}{|c|}{ Food and groceries } & \multicolumn{2}{|c|}{ Culture and leisure time } \\
\hline & Unexplained & SE & Unexplained & SE & Unexplained & SE & Unexplained & SE \\
\hline $1915-19$ & $4.51 * * *$ & 0.09 & $2.53 * * *$ & 0.09 & $1.85 * * *$ & 0.09 & $0.82 * * *$ & 0.09 \\
\hline $1920-24$ & $4.50 * * *$ & 0.09 & $2.99 * * *$ & 0.09 & $1.69 * * *$ & 0.21 & $1.65 * * *$ & 0.21 \\
\hline $1925-29$ & $4.39 * * *$ & 0.13 & $2.84 * * *$ & 0.13 & $1.83 * * *$ & 0.14 & $1.63 * * *$ & 0.14 \\
\hline $1930-34$ & $4.49 * * *$ & 0.05 & $2.74 * * *$ & 0.05 & $1.47 * * *$ & 0.10 & $1.73 * * *$ & 0.10 \\
\hline $1935-39$ & $4.58 * * *$ & 0.05 & $2.63 * * *$ & 0.05 & $1.25 * * *$ & 0.08 & $1.67 * * *$ & 0.08 \\
\hline $1940-44$ & $4.79 * * *$ & 0.08 & $2.40 * * *$ & 0.08 & $1.18 * * *$ & 0.08 & $1.73 * * *$ & 0.08 \\
\hline $1945-49$ & $4.88 * * *$ & 0.05 & $2.62 * * *$ & 0.05 & $1.27 * * *$ & 0.13 & $1.87 * * *$ & 0.13 \\
\hline $1950-54$ & $4.81 * * *$ & 0.05 & $2.55 * * *$ & 0.05 & $1.05 * * *$ & 0.14 & $1.94 * * *$ & 0.14 \\
\hline $1955-59$ & $4.67 * * *$ & 0.05 & $2.64 * * *$ & 0.05 & $0.80 * * *$ & 0.07 & $2.25 * * *$ & 0.07 \\
\hline $1960-64$ & $4.82 * * *$ & 0.10 & $2.59 * * *$ & 0.10 & $0.76 * * *$ & 0.13 & $2.14 * * *$ & 0.13 \\
\hline $1965-69$ & $4.56 * * *$ & 0.08 & $2.19 * * *$ & 0.08 & $0.92 * * *$ & 0.09 & $2.17 * * *$ & 0.09 \\
\hline $1970-74$ & $4.53 * * *$ & 0.10 & $2.08 * * *$ & 0.10 & 0.35 & 0.20 & $2.39 * * *$ & 0.20 \\
\hline $1975-79$ & $4.76 * * *$ & 0.15 & $1.77 * *$ & 0.15 & 0.18 & 0.14 & $2.09 * * *$ & 0.14 \\
\hline 1980-84 & $4.63 * * *$ & 0.06 & 1.91 & 0.06 & $1.01 * * *$ & 0.14 & $2.25 * * *$ & 0.14 \\
\hline $1985-89$ & $4.67 * * *$ & 0.11 & 2.31 & 0.11 & $1.04 * * *$ & 0.13 & $3.56^{* * *}$ & 0.13 \\
\hline 1990-94 & $4.54 * * *$ & 0.13 & 2.62 & 0.13 & $0.50^{*}$ & 0.20 & $1.69 * * *$ & 0.20 \\
\hline $20-24$ & 0.18 & 0.15 & -0.10 & 0.15 & $1.14 * * *$ & 0.29 & $-0.50 * * *$ & 0.29 \\
\hline $25-29$ & -0.23 & 0.07 & -0.19 & 0.07 & -0.01 & 0.12 & $-0.76 * * *$ & 0.12 \\
\hline $30-34$ & $-0.21 * * *$ & 0.03 & -0.21 & 0.03 & -0.11 & 0.15 & $-0.49 * * *$ & 0.15 \\
\hline $35-39$ & $-0.20 * * *$ & 0.02 & 0.03 & 0.02 & -0.05 & 0.12 & $-0.35^{* *}$ & 0.12 \\
\hline $40-44$ & $-0.16^{* * *}$ & 0.03 & 0.03 & 0.03 & -0.04 & 0.05 & 0.13 & 0.05 \\
\hline $45-49$ & -0.16 & 0.08 & -0.00 & 0.08 & -0.14 & 0.14 & $0.30 * *$ & 0.14 \\
\hline $50-54$ & $0.15 * * *$ & 0.04 & $0.22 * * *$ & 0.04 & -0.04 & 0.09 & $0.45 * * *$ & 0.09 \\
\hline $55-59$ & $0.35 * * *$ & 0.08 & 0.08 & 0.08 & $-0.32 * * *$ & 0.06 & $0.61 * * *$ & 0.06 \\
\hline 60-64 & $0.28 *$ & 0.14 & 0.13 & 0.14 & $-0.43 * *$ & 0.10 & $0.61 * * *$ & 0.10 \\
\hline 1971 & 0.22 & 0.05 & $0.3^{*}$ & 0.05 & $0.71 * *$ & 0.03 & -0.04 & 0.03 \\
\hline 1976 & 0.01 & 0.10 & 0.20 & 0.10 & $0.23 *$ & 0.12 & 0.08 & 0.12 \\
\hline 1981 & 0.02 & 0.12 & 0.05 & 0.12 & $0.20 * * *$ & 0.06 & 0.03 & 0.06 \\
\hline 1985 & 0.01 & 0.04 & -0.19 & 0.04 & $-0.49 * * *$ & 0.10 & -0.06 & 0.10 \\
\hline 1990 & -0.09 & 0.04 & $-0.30 * * *$ & 0.04 & -0.29 & 0.11 & $-0.18^{* *}$ & 0.11 \\
\hline 1995 & 0.01 & 0.03 & -0.03 & 0.03 & 0.08 & 0.06 & 0.01 & 0.06 \\
\hline 2001 & 0.04 & 0.04 & $0.27 * * *$ & 0.04 & $0.26 * * *$ & 0.08 & $0.12 *$ & 0.08 \\
\hline 2006 & 0.01 & 0.03 & 0.07 & 0.03 & 0.19 & 0.08 & 0.11 & 0.08 \\
\hline 2012 & -0.14 & 0.03 & $0.22 * * *$ & 0.03 & $0.40 * * *$ & 0.06 & -0.14 & 0.06 \\
\hline \multirow[t]{2}{*}{2016} & 0.24 & 0.05 & 0.14 & 0.05 & $0.27 * * *$ & 0.02 & 0.06 & 0.02 \\
\hline & Gap & SE & Gap & SE & Gap & SE & Gap & SE \\
\hline 1915-19 & $4.51 * * *$ & 0.09 & $2.53 * * *$ & 0.18 & $1.85 * * *$ & 0.09 & $0.82 * * *$ & 0.09 \\
\hline $1920-24$ & $4.50 * * *$ & 0.09 & $2.99 * * *$ & 0.31 & $1.69 * * *$ & 0.21 & $1.65 * * *$ & 0.21 \\
\hline $1925-29$ & $4.39 * * *$ & 0.13 & $2.84 * * *$ & 0.24 & $1.83 * * *$ & 0.14 & $1.63 * * *$ & 0.14 \\
\hline 1930-34 & $4.49 * * *$ & 0.05 & $2.74 * * *$ & 0.16 & $1.47 * * *$ & 0.10 & $1.73 * * *$ & 0.10 \\
\hline 1935-39 & $4.58 * * *$ & 0.05 & $2.63 * * *$ & 0.10 & $1.25 * * *$ & 0.08 & $1.67 * * *$ & 0.08 \\
\hline 1940-44 & $4.79 * * *$ & 0.08 & $2.40 * * *$ & 0.18 & $1.18 * * *$ & 0.08 & $1.73 * * *$ & 0.08 \\
\hline $1945-49$ & $4.88 * * *$ & 0.05 & $2.62 * * *$ & 0.06 & $1.27 * * *$ & 0.13 & $1.87 * * *$ & 0.13 \\
\hline $1950-54$ & $4.81 * * *$ & 0.05 & $2.55 * * *$ & 0.07 & $1.05^{* * *}$ & 0.14 & $1.94 * * *$ & 0.14 \\
\hline $1955-59$ & $4.67 * * *$ & 0.05 & $2.64 * * *$ & 0.09 & $0.80 * * *$ & 0.07 & $2.25 * * *$ & 0.07 \\
\hline 1960-64 & $4.82 * * *$ & 0.10 & $2.59 * * *$ & 0.13 & $0.76^{* * *}$ & 0.13 & $2.14 * * *$ & 0.13 \\
\hline $1965-69$ & $4.56 * * *$ & 0.08 & $2.19 * * *$ & 0.13 & $0.92 * * *$ & 0.09 & $2.17 * * *$ & 0.09 \\
\hline 1970-74 & $4.53 * * *$ & 0.10 & $2.08 * * *$ & 0.09 & 0.35 & 0.20 & $2.39 * * *$ & 0.20 \\
\hline
\end{tabular}


Table 3 (continued)

\begin{tabular}{|c|c|c|c|c|c|c|c|c|}
\hline & Gap & $\mathrm{SE}$ & Gap & $\mathrm{SE}$ & Gap & $\mathrm{SE}$ & Gap & $\mathrm{SE}$ \\
\hline $1975-79$ & $4.76 * * *$ & 0.15 & $1.77 * *$ & 0.61 & 0.18 & 0.14 & $2.09 * * *$ & 0.14 \\
\hline 1980-84 & $4.63 * * *$ & 0.06 & 1.91 & 0.13 & $1.01 * * *$ & 0.14 & $2.25 * * *$ & 0.14 \\
\hline 1985-89 & $4.67 * * *$ & 0.11 & 2.31 & 0.15 & $1.04 * * *$ & 0.13 & $3.56 * * *$ & 0.13 \\
\hline 1990-94 & $4.54 * * *$ & 0.13 & 2.62 & 0.19 & $0.50^{*}$ & 0.20 & $1.69 * * *$ & 0.20 \\
\hline $20-24$ & 0.18 & 0.15 & -0.10 & 0.50 & $1.14 * * *$ & 0.29 & $-0.50 * * *$ & 0.29 \\
\hline $25-29$ & -0.23 & 0.07 & -0.19 & 0.09 & -0.01 & 0.12 & $-0.76 * * *$ & 0.12 \\
\hline $30-34$ & $-0.21 * * *$ & 0.03 & -0.21 & 0.06 & -0.11 & 0.15 & $-0.49 * * *$ & 0.15 \\
\hline $35-39$ & $-0.20 * * *$ & 0.02 & 0.03 & 0.06 & -0.05 & 0.12 & $-0.35 * *$ & 0.12 \\
\hline $40-44$ & $-0.16^{* * *}$ & 0.03 & 0.03 & 0.10 & -0.04 & 0.05 & 0.13 & 0.05 \\
\hline $45-49$ & -0.16 & 0.08 & -0.00 & 0.05 & -0.14 & 0.14 & $0.30 * *$ & 0.14 \\
\hline $50-54$ & $0.15 * * *$ & 0.04 & $0.22 * * *$ & 0.04 & -0.04 & 0.09 & $0.45 * * *$ & 0.09 \\
\hline $55-59$ & $0.35 * * *$ & 0.08 & 0.08 & 0.19 & $-0.32 * * *$ & 0.06 & $0.61 * * *$ & 0.06 \\
\hline $60-64$ & $0.28 *$ & 0.14 & 0.13 & 0.26 & $-0.43^{* *}$ & 0.10 & $0.61 * * *$ & 0.10 \\
\hline 1971 & 0.22 & 0.05 & $0.3^{*}$ & 0.03 & $0.71 * *$ & 0.03 & -0.04 & 0.03 \\
\hline 1976 & 0.01 & 0.10 & 0.20 & 0.10 & $0.23 *$ & 0.12 & 0.08 & 0.12 \\
\hline 1981 & 0.02 & 0.12 & 0.05 & 0.16 & $0.20 * * *$ & 0.06 & 0.03 & 0.06 \\
\hline 1985 & 0.01 & 0.04 & -0.19 & 0.07 & $-0.49 * * *$ & 0.10 & -0.06 & 0.10 \\
\hline 1990 & -0.09 & 0.04 & $-0.30 * * *$ & 0.05 & -0.29 & 0.11 & $-0.18 * *$ & 0.11 \\
\hline 1995 & 0.01 & 0.03 & -0.03 & 0.06 & 0.08 & 0.06 & 0.01 & 0.06 \\
\hline 2001 & 0.04 & 0.04 & $0.27 * * *$ & 0.05 & $0.26 * * *$ & 0.08 & $0.12^{*}$ & 0.08 \\
\hline 2006 & 0.01 & 0.03 & 0.07 & 0.07 & 0.19 & 0.08 & 0.11 & 0.08 \\
\hline 2012 & -0.14 & 0.03 & $0.22 * * *$ & 0.03 & $0.40 * * *$ & 0.06 & -0.14 & 0.06 \\
\hline 2016 & 0.24 & 0.05 & 0.14 & 0.11 & $0.27 * * *$ & 0.02 & 0.06 & 0.02 \\
\hline
\end{tabular}

Statistical p-values are reported as $\mathrm{p}<0.05^{*}, \mathrm{p}<0.01^{* *}$ and $\mathrm{p}<0.001^{* * *}$ 
Table 4 APCGO estimates with control variables

\begin{tabular}{|c|c|c|c|c|c|c|c|c|}
\hline & \multicolumn{2}{|c|}{ Money income } & \multicolumn{2}{|c|}{ Money expenditures } & \multicolumn{2}{|c|}{ Food and groceries } & \multicolumn{2}{|l|}{$\begin{array}{l}\text { Culture and } \\
\text { leisure time }\end{array}$} \\
\hline & Explained & SE & Explained & SE & Explained & SE & Explained & SE \\
\hline 1915-19 & $0.99 * * *$ & 0.17 & $0.92 * * *$ & 0.09 & $0.97 * * *$ & 0.06 & $0.47 * * *$ & 0.14 \\
\hline $1920-24$ & $0.45^{* * *}$ & 0.07 & $0.77 * * *$ & 0.18 & $1.05^{* * *}$ & 0.26 & $-0.34 * * *$ & 0.04 \\
\hline $1925-29$ & $0.56^{* * *}$ & 0.05 & $0.48^{*}$ & 0.21 & $0.50 * * *$ & 0.09 & $0.40 * * *$ & 0.10 \\
\hline $1930-34$ & $0.73 * * *$ & 0.06 & $0.49 * * *$ & 0.05 & $0.39 *$ & 0.20 & 0.15 & 0.22 \\
\hline $1935-39$ & $0.35 * *$ & 0.13 & $0.35 * * *$ & 0.06 & 0.16 & 0.17 & 0.03 & 0.10 \\
\hline $1940-44$ & $0.37 * * *$ & 0.06 & $0.46^{* * *}$ & 0.09 & $0.21 *$ & 0.09 & 0.24 & 0.15 \\
\hline $1945-49$ & $0.42 * * *$ & 0.05 & $0.61 * * *$ & 0.04 & $0.16^{* * *}$ & 0.03 & $0.40 * * *$ & 0.03 \\
\hline $1950-54$ & $0.33 * * *$ & 0.04 & $0.65 * * *$ & 0.08 & $0.25^{* * *}$ & 0.07 & $0.39 * * *$ & 0.09 \\
\hline $1955-59$ & $0.22 * * *$ & 0.08 & $0.48 * * *$ & 0.04 & -0.10 & 0.07 & $0.62 * * *$ & 0.10 \\
\hline $1960-64$ & $0.13 * * *$ & 0.04 & $0.86^{* * * *}$ & 0.06 & -0.07 & 0.11 & $0.78 * * *$ & 0.15 \\
\hline $1965-69$ & $0.19 *$ & 0.07 & $0.53 * * *$ & 0.02 & -0.19 & 0.16 & $0.65 * * *$ & 0.11 \\
\hline 1970-74 & $0.21 * * *$ & 0.05 & $0.61 * * *$ & 0.29 & 0.01 & 0.22 & $0.75 * * *$ & 0.16 \\
\hline $1975-79$ & -0.20 & 0.06 & $1.16^{* * *}$ & 0.15 & -0.29 & 0.22 & $0.84 * * *$ & 0.08 \\
\hline 1980-84 & 0.10 & 0.05 & 0.57 & 0.11 & 0.20 & 0.10 & 0.45 & 0.11 \\
\hline 1985-89 & 1.50 & 0.08 & 0.90 & 0.09 & 0.00 & 0.07 & 2.27 & 0.18 \\
\hline 1990-94 & -0.04 & -0.02 & 1.04 & 0.06 & -0.10 & 0.09 & 0.41 & 0.03 \\
\hline $20-24$ & 0.84 & 0.11 & $-0.73 * * *$ & 0.12 & $0.68^{*}$ & 0.30 & $-0.85 * * *$ & 0.08 \\
\hline $25-29$ & $0.14 * *$ & 0.04 & -0.16 & 0.11 & 0.04 & 0.10 & $-0.57 * * *$ & 0.07 \\
\hline $30-34$ & 0.04 & 0.07 & $-0.19 * *$ & 0.04 & 0.03 & 0.15 & $-0.42 * *$ & 0.09 \\
\hline $35-39$ & -0.01 & 0.07 & $-0.08 *$ & 0.02 & 0.01 & 0.12 & -0.08 & 0.06 \\
\hline $40-44$ & 0.07 & 0.06 & 0.01 & 0.04 & -0.13 & 0.08 & $0.06^{* *}$ & 0.02 \\
\hline $45-49$ & $-0.15 * *$ & 0.03 & 0.17 & 0.10 & -0.20 & 0.10 & $0.05 * *$ & 0.02 \\
\hline $50-54$ & -0.22 & 0.08 & $0.23 * *$ & 0.08 & -0.03 & 0.09 & $0.34 * * *$ & 0.05 \\
\hline $55-59$ & $-0.31 * * *$ & 0.04 & $0.31 * * *$ & 0.06 & -0.22 & 0.17 & $0.72 * * *$ & 0.08 \\
\hline $60-64$ & $-0.40^{*}$ & 0.11 & $0.45 * * *$ & 0.14 & -0.17 & 0.24 & $0.78 * * *$ & 0.10 \\
\hline 1971 & $0.15^{* *}$ & 0.03 & $-0.15^{*}$ & 0.04 & 0.03 & 0.01 & 0.03 & 0.02 \\
\hline 1976 & -0.04 & 0.03 & -0.02 & 0.01 & $-0.00 *$ & 0.08 & $-0.10 * * *$ & 0.01 \\
\hline 1981 & -0.01 & 0.02 & -0.09 & 0.03 & 0.14 & 0.06 & $0.21 * * *$ & 0.05 \\
\hline 1985 & $0.11 * *$ & 0.04 & $0.16^{* * *}$ & 0.01 & -0.13 & 0.12 & -0.14 & 0.08 \\
\hline 1990 & 0.02 & 0.03 & 0.03 & 0.04 & -0.07 & 0.06 & $0.03 * * *$ & 0.00 \\
\hline 1995 & $-0.13^{*}$ & 0.03 & -0.12 & 0.05 & -0.01 & 0.11 & 0.02 & 0.04 \\
\hline 2001 & 0.05 & 0.03 & 0.03 & 0.02 & 0.07 & 0.09 & -0.02 & 0.02 \\
\hline 2006 & 0.24 & 0.06 & 0.01 & 0.08 & 0.00 & 0.04 & 0.01 & 0.01 \\
\hline 2012 & -0.09 & 0.07 & -0.24 & 0.05 & 0.23 & 0.03 & 0.11 & 0.07 \\
\hline \multirow[t]{2}{*}{2016} & 0.13 & 0.04 & -0.07 & 0.02 & -0.06 & 0.05 & -0.14 & 0.02 \\
\hline & Unexplained & SE & Unexplained & SE & Unexplained & SE & Unexplained & SE \\
\hline 1915-19 & $3.58 * * *$ & 0.03 & $1.56^{* * * *}$ & 0.16 & $0.93 * * *$ & 0.07 & $0.26 * *$ & 0.08 \\
\hline $1920-24$ & $4.06^{* * *}$ & 0.17 & $2.40 * * *$ & 0.18 & $0.47 * *$ & 0.17 & $1.71 * * *$ & 0.28 \\
\hline $1925-29$ & $3.85^{* * *}$ & 0.08 & $2.54 * * *$ & 0.10 & $1.28 * * *$ & 0.11 & $1.11 * * *$ & 0.09 \\
\hline 1930-34 & $3.77 * * *$ & 0.10 & $2.28 * * *$ & 0.09 & $1.18 * * *$ & 0.22 & $1.60 * * *$ & 0.08 \\
\hline 1935-39 & $4.16^{* * *}$ & 0.10 & $2.37 * * *$ & 0.16 & $1.09 * * *$ & 0.20 & $1.42 * * *$ & 0.09 \\
\hline 1940-44 & $4.42 * * *$ & 0.07 & $2.01 * * *$ & 0.03 & $0.88 * * *$ & 0.08 & $1.33 * * *$ & 0.15 \\
\hline $1945-49$ & $4.42 * * *$ & 0.07 & $1.96 * * *$ & 0.05 & $1.07 * * *$ & 0.12 & $1.36 * * *$ & 0.01 \\
\hline $1950-54$ & $4.42 * * *$ & 0.03 & $1.74 * * *$ & 0.07 & $0.84 * * *$ & 0.06 & $1.47 * * *$ & 0.07 \\
\hline $1955-59$ & $4.49 * * *$ & 0.06 & $2.03 * * *$ & 0.18 & $0.96 * * *$ & 0.13 & $1.69 * * *$ & 0.17 \\
\hline 1960-64 & $4.68 * * *$ & 0.04 & $1.49 * * *$ & 0.14 & $0.85^{* * *}$ & 0.17 & $1.54 * * *$ & 0.14 \\
\hline $1965-69$ & $4.36 * * *$ & 0.08 & $1.62 * * *$ & 0.12 & $1.05 * * *$ & 0.25 & $1.52 * * *$ & 0.02 \\
\hline
\end{tabular}


Table 4 (continued)

\begin{tabular}{|c|c|c|c|c|c|c|c|c|}
\hline & Unexplained & SE & Unexplained & SE & Unexplained & SE & Unexplained & SE \\
\hline $1970-74$ & $4.45^{* * *}$ & 0.08 & $1.39 * * *$ & 0.15 & $0.38 *$ & 0.16 & $1.77 * * *$ & 0.32 \\
\hline $1975-79$ & $4.98 * * *$ & 0.24 & 0.52 & 0.44 & 0.23 & 0.57 & $1.87 * * *$ & 0.41 \\
\hline 1980-84 & $4.53 * * *$ & 0.10 & $1.39 * * *$ & 0.05 & $1.01 * * *$ & 0.19 & $1.79 * * *$ & 0.10 \\
\hline $1985-89$ & $3.03 * * *$ & 0.07 & $1.44 * * *$ & 0.11 & $1.23 * * *$ & 0.31 & $1.32 * * *$ & 0.23 \\
\hline 1990-94 & $4.40 * * *$ & 0.19 & $1,73^{* * *}$ & 0.10 & $0.95 * * *$ & 0.25 & $1.31 * * *$ & 0.11 \\
\hline $20-24$ & $-0.63 * * *$ & 0.10 & $0.90 * *$ & 0.29 & 0.58 & 0.43 & -0.26 & 0.32 \\
\hline $25-29$ & $-0.39 * * *$ & 0.07 & $0.10 * *$ & 0.04 & -0.06 & 0.18 & $-0.26^{*}$ & 0.07 \\
\hline $30-34$ & $-0.35 * * *$ & 0.06 & $0.13 *$ & 0.13 & -0.12 & 0.13 & 0.02 & 0.06 \\
\hline $35-39$ & $-0.27 * * *$ & 0.05 & 0.19 & 0.12 & -0.20 & 0.13 & -0.18 & 0.07 \\
\hline $40-44$ & -0.17 & 0.06 & 0.03 & 0.09 & 0.04 & 0.08 & 0.1 & 0.11 \\
\hline $45-49$ & $0.11 * * *$ & 0.02 & -0.13 & 0.09 & 0.05 & 0.10 & $0.46^{* * *}$ & 0.08 \\
\hline $50-54$ & $0.40 * * *$ & 0.10 & $-0.16^{*}$ & 0.04 & -0.05 & 0.10 & 0.04 & 0.11 \\
\hline $55-59$ & $0.58 * * *$ & 0.02 & -0.36 & 0.17 & -0.03 & 0.21 & 0.12 & 0.15 \\
\hline $60-64$ & $0.73 * * *$ & 0.06 & -0.70 & 0.24 & -0.22 & 0.30 & -0.07 & 0.16 \\
\hline 1971 & 0.05 & 0.04 & 0.53 & 0.07 & 0.62 & 0.05 & -0.08 & 0.06 \\
\hline 1976 & 0.02 & 0.06 & $0.30 * * *$ & 0.05 & 0.26 & 0.17 & $0.21 * * *$ & 0.03 \\
\hline 1981 & 0.05 & 0.04 & 0.03 & 0.03 & 0.02 & 0.11 & $-0.15^{* * *}$ & 0.03 \\
\hline 1985 & -0.05 & 0.06 & $-0.34 *$ & 0.09 & -0.37 & 0.10 & -0.01 & 0.10 \\
\hline 1990 & $-0.12 * * *$ & 0.02 & $-0.37 * * *$ & 0.03 & -0.21 & 0.08 & -0.20 & 0.07 \\
\hline 1995 & $0.12 * * *$ & 0.03 & 0.10 & 0.05 & 0.15 & 0.14 & -0.04 & 0.04 \\
\hline 2001 & -0.02 & 0.05 & $0.27 * * *$ & 0.06 & 0.15 & 0.17 & $0.19 * * *$ & 0.05 \\
\hline 2006 & -0.24 & 0.05 & 0.16 & 0.09 & 0.14 & 0.04 & 0.03 & 0.04 \\
\hline 2012 & 0.01 & 0.11 & 0.44 & 0.06 & 0.24 & 0.01 & -0.14 & 0.05 \\
\hline \multirow[t]{2}{*}{2016} & 0.03 & 0.07 & 0.20 & 0.10 & 0.27 & 0.02 & 0.15 & 0.04 \\
\hline & Gap & SE & Gap & SE & Gap & SE & Gap & SE \\
\hline 1915-19 & $3.23 * * *$ & 0.06 & $1.56^{* * *}$ & 0.01 & $1.80^{* * *}$ & 0.10 & $0.45^{* * *}$ & 0.08 \\
\hline 1920-24 & $4.52 * * *$ & 0.14 & $3.16 * * *$ & 0.01 & $1.51 * * *$ & 0.14 & $1.37 * * *$ & 0.27 \\
\hline $1925-29$ & $4.41 * * *$ & 0.08 & $3.02 * * *$ & 0.15 & $1.78 * * *$ & 0.02 & $1.51 * * *$ & 0.18 \\
\hline 1930-34 & $4.50 * * *$ & 0.05 & $2.77 * * *$ & 0.06 & $1.57 * * *$ & 0.05 & $1.75 * * *$ & 0.22 \\
\hline 1935-39 & $4.52 * * *$ & 0.03 & $2.72 * * *$ & 0.10 & $1.25 * * *$ & 0.05 & $1.45^{* * *}$ & 0.05 \\
\hline 1940-44 & $4.79 * * *$ & 0.04 & $2.47 * * *$ & 0.06 & $1.09 * * *$ & 0.09 & $1.57 * * *$ & 0.00 \\
\hline $1945-49$ & $4.84 * * *$ & 0.04 & $2.58 * * *$ & 0.03 & $1.23 * * *$ & 0.10 & $1.76 * * *$ & 0.02 \\
\hline $1950-54$ & $4.76^{* * *}$ & 0.07 & $2.39 * * *$ & 0.03 & $1.09 * * *$ & 0.08 & $1.86^{* * *}$ & 0.16 \\
\hline $1955-59$ & $4.71 * * *$ & 0.08 & $2.51 * * *$ & 0.15 & $0.86 * * *$ & 0.10 & $2.31 * * *$ & 0.12 \\
\hline 1960-64 & $4.82 * * *$ & 0.07 & $2.35^{* * *}$ & 0.18 & $0.78 * * *$ & 0.09 & $2.33 * * *$ & 0.16 \\
\hline 1965-69 & $4.55 * * *$ & 0.00 & $2.15 * * *$ & 0.11 & $0.86 * * *$ & 0.12 & $2.17 * * *$ & 0.13 \\
\hline 1970-74 & $4.66^{* * *}$ & 0.07 & $2.00 * * *$ & 0.15 & $0.39 * * *$ & 0.06 & $2.52 * * *$ & 0.23 \\
\hline 1975-79 & $4.78^{* * *}$ & 0.21 & $1.67 * * *$ & 0.30 & -0.06 & 0.36 & $2.71 * * *$ & 0.45 \\
\hline 1980-84 & 3.70 & 0.14 & 1.84 & 0.06 & 1.25 & 0.04 & 2.08 & 0.18 \\
\hline 1985-89 & 4.67 & 0.29 & 3.30 & 0.19 & 1.15 & 0.04 & 2.76 & 0.11 \\
\hline 1990-94 & 2.81 & 0.05 & 1.98 & 0.14 & 0.81 & 0.07 & 1.57 & 0.09 \\
\hline $20-24$ & $0.21 * * *$ & 0.05 & 0.17 & 0.27 & $1.26 * * *$ & 0.16 & $-1.11 * *$ & 0.25 \\
\hline $25-29$ & $-0.25 * * *$ & 0.03 & -0.06 & 0.16 & -0.02 & 0.17 & $-0.83 * * *$ & 0.06 \\
\hline $30-34$ & $-0.31 * * *$ & 0.05 & -0.07 & 0.14 & -0.10 & 0.05 & $-0.41 * *$ & 0.03 \\
\hline $35-39$ & -0.28 & 0.09 & 0.11 & 0.12 & $-0.19 * * *$ & 0.03 & -0.27 & 0.10 \\
\hline $40-44$ & $-0.11 * * *$ & 0.01 & 0.04 & 0.07 & -0.09 & 0.04 & 0.19 & 0.13 \\
\hline $45-49$ & -0.04 & 0.02 & 0.04 & 0.10 & $-0.15 * * *$ & 0.02 & $0.51 * * *$ & 0.07 \\
\hline $50-54$ & $0.17 * * *$ & 0.03 & 0.07 & 0.09 & -0.08 & 0.04 & $0.38 * *$ & 0.14 \\
\hline $55-59$ & $0.27 * * *$ & 0.02 & -0.05 & 0.10 & $-0.25 * * *$ & 0.04 & $0.84 * * *$ & 0.09 \\
\hline
\end{tabular}


Table 4 (continued)

\begin{tabular}{|c|c|c|c|c|c|c|c|c|}
\hline & Gap & SE & Gap & SE & Gap & SE & Gap & SE \\
\hline $60-64$ & $0.34 * * *$ & 0.05 & -0.25 & 0.11 & $-0.39 * * *$ & 0.06 & $0.70 * *$ & 0.24 \\
\hline 1971 & 0.20 & 0.04 & 0.39 & 0.07 & 0.64 & 0.04 & -0.05 & 0.04 \\
\hline 1976 & -0.02 & 0.05 & $0.29 * * *$ & 0.07 & $0.26^{* *}$ & 0.09 & $0.12 * * *$ & 0.03 \\
\hline 1981 & 0.03 & 0.04 & -0.05 & 0.05 & 0.15 & 0.08 & 0.062 & 0.06 \\
\hline 1985 & 0.06 & 0.04 & -0.18 & 0.08 & $-0.50 * * *$ & 0.04 & $-0.15^{*}$ & 0.04 \\
\hline 1990 & $-0.10 * * *$ & 0.02 & $-0.34 * * *$ & 0.01 & $-0.28 * *$ & 0.06 & -0.18 & 0.07 \\
\hline 1995 & -0.01 & 0.04 & $-0.02 * *$ & 0.01 & 0.14 & 0.11 & $-0.02 * * *$ & 0.02 \\
\hline 2001 & 0.03 & 0.04 & $0.30 * * *$ & 0.03 & $0.23 *$ & 0.11 & $0.17 * * *$ & 0.03 \\
\hline 2006 & -0.00 & 0.03 & 0.17 & 0.07 & 0.14 & 0.02 & 0.04 & 0.03 \\
\hline 2012 & -0.08 & 0.04 & 0.20 & 0.08 & 0.47 & 0.03 & -0.03 & 0.05 \\
\hline 2016 & 0.16 & 0.04 & 0.12 & 0.10 & 0.21 & 0.03 & 0.02 & 0.06 \\
\hline
\end{tabular}

Statistical p-values are reported as $\mathrm{p}<0.05^{*}, \mathrm{p}<0.01^{* *}$ and $\mathrm{p}<0.001^{* * *}$

\begin{abstract}
Acknowledgements The research was conducted using Finnish Household Expenditure Surveys (HES), obtained after signing confidentiality agreements and given data access permissions from the Statistics Finland. Participants in the HESs have given their informed consent, and adequate steps have been taken in this study to protect participants' anonymity.
\end{abstract}

Funding Open access funding provided by University of Turku (UTU) including Turku University Central Hospital. This research was supported by the Strategic Research Council of the Academy of Finland (Decision Numbers: 293103 and 314250) and by the Academy of Finland Flagship Programme (Decision Number: 320162).

Data Availability The research was conducted using Finnish Household Expenditure Surveys (HES), obtained after signing confidentiality agreements and given data access permissions from the Statistics Finland. Data availability is restricted by Statistics Finland.

Code Availability This research was conducted by using STATA 15.1. MP -version and used APCGO package developed by Louis Chauvel, Anne Hartung and Eyal Bar-Haim.

\section{Declarations}

Conflict of interest All the authors declared that they have no conflict of interest.

Open Access This article is licensed under a Creative Commons Attribution 4.0 International License, which permits use, sharing, adaptation, distribution and reproduction in any medium or format, as long as you give appropriate credit to the original author(s) and the source, provide a link to the Creative Commons licence, and indicate if changes were made. The images or other third party material in this article are included in the article's Creative Commons licence, unless indicated otherwise in a credit line to the material. If material is not included in the article's Creative Commons licence and your intended use is not permitted by statutory regulation or exceeds the permitted use, you will need to obtain permission directly from the copyright holder. To view a copy of this licence, visit http://creativecommons. org/licenses/by/4.0/.

\section{References}

Aguiar, M., \& Bils, M. (2015). Has consumption inequality mirrored income inequality? American Economic Review, 105(9), 2725. https://doi.org/10.1257/aer.20120599

Attanasio, O., Hurst, E., \& Pistaferri, L. (2014). The evolution of income, consumption, and leisure inequality in the United States, 1980-2010. National Bureau of Economic Research. https://doi. org/10.3386/w17982

Attanasio, O. P., \& Browning, M. (1993). Consumption over the life cycle and over the business cycle (Working Paper No 4453). National Bureau of Economic Research. https://doi.org/10.3386/ w4453

Autor, D. H., Katz, L. F., \& Kearney, M. S. (2005). Trends in US wage inequality: Re-assessing the revisionists (Working Paper No. 11627). National Bureau of Economic Research. https://doi. org/10.3386/w11627

Bar-Haim, E., Chauvel, L., Gornick, J., \& Hartung, A. (2018). The persistence of the gender earnings gap: Cohort trends and the role of education in twelve countries (No. 737; LIS Working Papers). LIS Cross-National Data Center in Luxembourg. Retrieved from https://ideas.repec.org/p/lis/liswps/737.html

Bar-Haim, E., Chauvel, L., \& Hartung, A. (2019). More necessary and less sufficient: An age-period-cohort approach to overeducation in comparative perspective. High Educ., 78, 479.

Becker, G. S., \& Murphy, K. M. (2009). Social economics: Market behavior in a social environment. Harvard University Press.

Bihagen, E. (1999). How do classes make use of their incomes? Social Indicators Research, 47(2), 119-151. https://doi.org/10.1023/A: 1006891324905

Bihagen, E., \& Katz-Gerro, T. (2000). Culture consumption in Sweden: The stability of gender differences. Poetics, 27(5-6), 327-349. https://doi.org/10.1016/S0304-422X(00)00004-8

Bils, M., \& Aguiar, M. (2010). Has consumption inequality mirrored income inequality? (No. 1334; 2010 Meeting Papers). Society for Economic Dynamics. Retrieved from https://ideas.repec. org/p/red/sed010/1334.html

Blinder, A. S. (1973). Wage discrimination: Reduced form and structural estimates. The Journal of Human Resources, 8(4), 436-455. https://doi.org/10.2307/144855

Blomgren, J. K., Hiilamo, H., Kangas, O., \& Niemelä, M. (2014). Finland: growing inequality with contested consequences in changing inequalities in rich countries. In: B. Nolan et al. (Ed.), Changing inequalities and societal impacts in rich 
countries: Thirty countries' experiences, Oxford University Press, Oxford, (pp. 222-247).

Blow, L., Leicester, A., \& Oldfield, Z. (2004). Consumption trends in the UK, 1975 - 99 (Research Report No. R65). IFS Report. https://doi.org/10.1920/re.ifs.2004.0065

Blundell, R. (1988). Consumer behaviour: Theory and empirical evidence-a survey. Economic Journal, 98(389), 16-65. https:// doi.org/10.2307/2233510

Blundell, R., \& Preston, I. (1995). Income, expenditure and the living standards of UK households. Fiscal Studies, 16(3), 40-54. https://doi.org/10.1111/j.1475-5890.1995.tb00226.x

Blundell, R., \& Preston, I. (1998). Consumption inequality and income uncertainty. The Quarterly Journal of Economics, 113(2), 603-640. https://doi.org/10.1162/003355398555694

Bögenhold, D., \& Fachinger, U. (2000). The social embeddedness of consumption: Towards the relationship of income and expenditures over time in Germany (Working papers of the ZeS 06/2000). University of Bremen, Centre for Social Policy Research (ZeS). Retrieved from https://mpra.ub.uni-muenchen. $\mathrm{de} / \mathrm{id} / \mathrm{eprint} / 1128$

Chai, A., Rohde, N., \& Silber, J. (2015). Measuring the diversity of household spending patterns. Journal of Economic Surveys. https://doi.org/10.1111/joes.12066

Chauvel, L., \& Schroder, M. (2014). Generational inequalities and welfare regimes. Social Forces, 92(4), 1259-1283. https://doi. org/10.1093/sf/sot156

Chauvel, L. (2016). The intensity and shape of inequality: The ABG method of distributional analysis. Review of Income and Wealth, 62(1), 52-68. https://doi.org/10.1111/roiw.12161

Chauvel, L., \& Bar-Haim, E. (2017). ISOGRAPH: Stata module to compute inequality over logit ranks of social hierarchy. Boston College Department of Economics. Retrieved from https://ideas. repec.org/c/boc/bocode/s458255.html

Chauvel, L., Hartung A., \& Bar-Haim, E. (2017). APCGO: Stata module to calculate age-period-cohort effects for the gap between two groups (based on a Blinder-Oaxaca decomposition), including trends for each parameter. Retrieved from https://ideas.repec. org/c/boc/bocode/s458331.html

Chen, R., Ann Wong, K., \& Chew Lee, H. (2001). Age, period, and cohort effects on life insurance purchases in the U.S. The Journal of Risk and Insurance, 68(2), 303-327. https://doi.org/10.2307/ 2678104

Cohen, P. N. (2016). Replacing housework in the service economy: Gender, class, and race-ethnicity in service spending. Gender \& Society, 12(2), 219-231. https://doi.org/10.1177/0891243980 12002006

Copas, J. (1999). The effectiveness of risk scores: The logit rank plot. Journal of the Royal Statistical Society: Series C (applied Statistics), 48(2), 165-183. https://doi.org/10.1111/1467-9876.00147

Cutler, D. M., Katz, L. F., Card, D., \& Hall, R. E. (1991). Macroeconomic performance and the disadvantaged. Brookings Papers on Economic Activity, 1991(2), 1-74. https://doi.org/10.2307/ 2534589

Deaton, A. (1992). Understanding consumption. Clarendon Press.

Deaton, A., \& Muellbauer, J. (1980). Economics and consumer behavior. Cambridge University Press.

Deutsch, J., Guio, A.-C., Pomati, M., \& Silber, J. (2015). Material deprivation in Europe: Which expenditures are curtailed first? Social Indicators Research, 120(3), 723-740. https://doi.org/10. 1007/s11205-014-0618-6

Dew-Becker, I., \& Gordon, R. J. (2005). Where did the productivity growth go? Inflation Dynamics and the Distribution of Income (Working Paper No. 11842). National Bureau of Economic Research. https://doi.org/10.3386/w11842.

Douglas, M., \& Isherwood, B. C. (1996). The world of goods: Towards an anthropology of consumption. Psychology Press.
Dutt, P., \& Padmanabhan, V. (2011). Crisis and consumption smoothing. Marketing Science, 30(3), 491-512. https://doi.org/10.1287/ mksc. 1100.0630

Erlandsen, S., \& Nymoen, R. (2008). Consumption and population age structure. Journal of Population Economics, 21(3), 505-520.

Fan, J. X., \& Lewis, J. K. (1999). Budget allocation patterns of African Americans. The Journal of Consumer Affairs. https://doi.org/10. 1111/j.1745-6606.1999.tb00764.x

Felson, M. (1976). The differentiation of material life styles: 1925 to 1966. Social Indicators Research, 3(3), 397-421. https://doi.org/ 10.1007/BF00304122

Fellman, J., Jäntti, M., \& Lambert, P. J. (1999). Optimal tax-transfer systems and redistributive policy. Scandinavian Journal of Economics, 101(1), 115-126. https://doi.org/10.1111/1467-9442. 00144

Fernandez-Villaverde, J., \& Krueger, D. (2002). Consumption over the life cycle: facts from Consumer Expenditure Survey Data (Working Paper No. 9382). National Bureau of Economic Research. https://doi.org/10.3386/w9382.

Fisher, J. D., Johnson, D. S., \& Smeeding, T. M. (2013). Measuring the trends in inequality of individuals and families: Income and consumption. The American Economic Review, 103(3), 184-188. https://doi.org/10.1257/aer.103.3.184

Fisher, J., Johnson, D., \& Smeeding, T. M. (2015). Inequality of income and consumption in the U.S.: Measuring the trends in inequality from 1984 to 2011 for the same individuals. The Review of Income and Wealth, 61(4), 630-650. https://doi.org/ 10.1111/roiw.12129

Friedman, M. (1957). A theory of the consumption function. National Bureau of Economic Research. https://doi.org/10. $1515 / 9780691188485$

Freedman, M. (2017). Are recent generations catching up or falling behind? Trends in inter-generational inequality (LIS Working Paper No. 689). LIS Cross-National Data Center in Luxembourg. Retrieved from https://econpapers.repec.org/paper/lisli swps/689.htm

Gardes, F., \& Starzec, C. (2004). Household demand patterns in France 1980-1995 (No. wp6; DEMPATEM Working Papers). Amsterdam Institute for Advanced Labour Studies. Retrieved from https://ideas.repec.org/p/aia/dempat/wp6.html

Goldin, C., \& Katz, L. F. (2007). Long-run changes in the U.S. wage structure: narrowing, widening, polarizing (Working Paper No. 13568). National Bureau of Economic Research. https://doi. org/10.3386/w13568.

Gourinchas, P.-O., \& Parker, J. A. (2002). Consumption over the life cycle. Econometrica, 70(1), 47-89. https://doi.org/10.1111/ 1468-0262.00269

Haugtvedt, C. P., Petty, R. E., \& Cacioppo, J. T. (1992). Need for cognition and advertising: Understanding the role of personality variables in consumer behavior. Journal of Consumer Psychology, 1(3), 239-260. https://doi.org/10.1016/S10577408(08)80038-1

Heathcote, J., Perri, F., \& Violante, G. L. (2010). Unequal we stand: An empirical analysis of economic inequality in the United States, 1967-2006. Review of Economic Dynamics, 13(1), 15-51. https://doi.org/10.1016/j.red.2009.10.010

Herpin, N., \& Verger, D. (2000). La consommation des Français: Alimentation, habillement, logement (Vol. 279). Editions La Découverte. https://doi.org/10.2307/3323040.

Heslop, L. A. (1987). Cohort analysis of the expenditure patterns of the elderly. ACR North American Advances, NA-14. Retrieved from https:///www.acrwebsite.org/volumes/6763/volumes/v14/ NA-14

Hirsch, F. (2005). Social limits to growth. Routledge.

Holm, L., Ekström, M. P., Gronow, J., Kjærnes, U., Lund, T. B., Mäkelä, J., \& Niva, M. (2012). The modernisation of 
Nordic eating: Studying changes and stabilities in eating patterns. Anthropology of Food, S7, 2-14. https://doi.org/10.4000/ aof.6997

Howe, N., \& Strauss, W. (1992). The new generation gap. AtlanticBoston, 270, 67-67.

Jann, B. (2008). The Blinder-Oaxaca decomposition for linear regression models. The Stata Journal, 8(4), 453-479. https:// doi.org/10.1177/1536867X0800800401

Johnson, D., \& Shipp, S. (1997). Trends in inequality using consumption-expenditures: The U.S.1 from 1960 to 1993. Review of Income and Wealth, 43(2), 133-152. https://doi.org/10. 1111/j.1475-4991.1997.tb00211.x

Jäntti, M., Pirttilä, J., \& Rönkkö, R. (2020). The determinants of redistribution around the world. Review of Income and Wealth, 66(1), 59-73. https://doi.org/10.1111/roiw.12406

Karonen, E., \& Niemelä, M. (2020). Life course perspective on economic shocks and income inequality through age-periodcohort analysis: Evidence from Finland. Review of Income and Wealth, 66(2), 287-310. https://doi.org/10.1111/roiw.12409

Katz-Gerro, T., \& Shavit, Y. (1998). The stratification of leisure and taste: Classes and lifestyles in Israel. European Sociological Review, 14(4), 369-386. https://doi.org/10.1093/oxfordjour nals.esr.a018245

Katz-Gerro, T. (2002). Highbrow cultural consumption and class distinction in Italy, Israel, West Germany, Sweden, and the United States. Social Forces, 81(1), 207-229.

Katz-Gerro, T. (2003). Consumption-based inequality: Household expenditures and possession of goods in Israel, 1986-1998. In R. Shechter (Ed.), Transitions in domestic consumption and family life in the modern middle east (pp. 167-189). Palgrave Macmillan.

Katz-Gerro, T., \& Talmud, I. (2005). Structural analysis of a consumption-based stratification indicator: Relational proximity of household expenditures. Social Indicators Research, 73(1), 109-132. https://doi.org/10.1007/s11205-004-6167-7

Koelln, K., Rubin, R. M., \& Picard, M. S. (1995). Vulnerable elderly households: Expenditures on necessities by older Americans. Social Science Quarterly, 76(3), 619-633.

Kolsrud, J., Landais, C., \& Spinnewijn, J. (2017). Studying consumption patterns using registry data: Lessons from Swedish administrative data (SSRN Scholarly Paper ID 3061835). Social Science Research Network. Retrieved from https://papers.ssrn.com/abstr act $=3061835$

Krueger, D., \& Perri, F. (2006). Does income inequality lead to consumption inequality? Evidence and theory. The Review of Economic Studies, 73(1), 163-193. https://doi.org/10.1111/j.1467937X.2006.00373.X

Kuhn, P., \& Lozano, F. (2008). The expanding workweek? Understanding trends in long work hours among U.S. men, 1979-2006. Journal of Labor Economics, 26(2), 311-343. https://doi.org/10. 3386/w11895

Langlois, R. N. (2001). Knowledge, consumption, and endogenous growth. In U. Witt (Ed.), Escaping satiation. Springer.

Langlois, S. (2002). Nouvelles orientations en sociologie de la consommation. L'annee Sociologique, 52(1), 83-103. https://doi.org/10. 3917/anso.021.0083

Langlois, S. (2003). Structures de la consommation au Canada : Perspectives transversales et longitudinales. Sociologie Et Sociétés, 35(1), 221-242. https://doi.org/10.7202/008518ar

Lewbel, A. (1999). Engel curves. In S. N. Durlauf \& L. E. Blume (Eds.), The new Palgrave dictionary of economics (2nd ed.). Palgrave Macmillian.

Lührmann, M. (2006). Population aging and the demand for goods \& services [Working paper]. No 5095, MEA discussion paper series from Munich Center for the Economics of Aging (MEA) at the
Max Planck Institute for Social Law and Social Policy. Retrieved from http://ub-madoc.bib.uni-mannheim.de/1288

Mckenzie, D., Schargrodsky, E., \& Cruces, G. (2011). Buying less but shopping more: The use of nonmarket labor during a crisis. Economía, 11(2), 1-43. https://doi.org/10.1353/eco.2011.0004

Mannheim, K. (1928), Das Problem der Generationen. Bayerische Staatsbibliothek.

Marx, I., Salanauskaite, L., \& Verbist, G. (2013). The paradox of redistribution revisited: And that it may rest in peace? IZA Discussion Paper Series No. 7414. Retrieved from http://ftp.iza.org/ dp7414.pdf

Meyer, B. D., \& Sullivan, J. X. (2013). Consumption and income inequality and the great recession. The American Economic Review, 103(3), 178-183.

Nicosia, F. M., \& Mayer, R. N. (1976). Toward a sociology of consumption. Journal of Consumer Research, 3(2), 65-75. https:// doi.org/10.1086/208653

Noll, H.-H., \& Weick, S. (2005). Markante unterschiede in den verbrauchsstrukturen verschiedener einkommenspositionen trotz konvergenz: Analysen zu ungleichheit und strukturwandel des konsums. Informationsdienst Soziale Indikatoren, 34, 1-5. https://doi.org/10.15464/isi.34.2005.1-5

Oaxaca, R. L. (1973). Male-female wage differentials in urban labor markets. International Economic Review, 14(3), 693-709. https:// doi.org/10.2307/2525981

Oaxaca, R. L., \& Ransom, M. R. (1994). On discrimination and the decomposition of wage differentials. Journal of Econometrics, 61(1), 5-21. https://doi.org/10.1016/0304-4076(94)90074-4

OECD. (2011). Divided we stand: Why inequality keeps rising. OECD Publishing.

Ranieri, R., \& Ramos, R. A. (2013). Inclusive growth: Building up a concept (No. 104; Working Papers). International Policy Centre for Inclusive Growth. Retrieved from http://hdl.handle.net/ $10419 / 71821$

Raper, K. C., Wanzala, M. N., Rodolfo, M., \& Nayga, J. (2002). Food expenditures and household demographic composition in the US: A demand systems approach. Applied Economics, 34(8), 981-992. https://doi.org/10.1080/00036840110061959

Räsänen, P. (2003). In the twilight of social structures: A mechanismbased study of contemporary consumer behavior . Doctoral dissertation, University of Turku. University of Turku.

Reither, E. N., Hauser, R. M., \& Yang, Y. (2009). Do birth cohorts matter? Age-period- cohort analyses of the obesity epidemic in the United States. Social Science \& Medicine, 69(10), 1439-1448. https://doi.org/10.1016/j.socscimed.2009.08.040

Rindfleisch, A. (1994). Cohort generational influences on consumer socialization. ACR North American Advances, 21, 470-476.

Salcedo, A. M., \& Izquierdo Llanes, G. (2020). Refining the monetary poverty indicators under a join income-consumption statistical approach: An application to Spain based on empirical data. Social Indicators Research, 147(2), 501-516. https://doi.org/10. 1007/s11205-019-02159-Z

Schettkat, R., \& Deelen, M. (2004). Household demand patterns in West Germany: 1978- 1993. Consumption patterns and demand for services [DEMPATEM Working Paper]. Amsterdam Institute for Advanced Labour Studies. Retrieved from https://econpapers. repec.org/paper/aiadempat/wp5.htm

Semyonov, M., \& Lewin-Epstein, N. (2013). Ways to richness: Determination of household wealth in 16 countries. European Sociological Review, 29(6), 1134-1148. https://doi.org/10.1093/esr/ jet001

Semyonov, M., Lewin-Epstein, N., \& Spilerman, S. (1996). The material possessions of Israeli ethnic groups. European Sociological Review, 12(3), 289-301. https://doi.org/10.1093/oxfordjournals. esr.a018193

Slater, D. (1999). Consumer culture and modernity. Wiley. 
Slesnick, D. T. (1993). Gaining ground: Poverty in the postwar United States. Journal of Political Economy, 101(1), 1-38. https://doi. org/10.1086/261864

Slesnick, D. T. (2001). Consumption and social welfare. Cambridge University Press.

Spilerman, S. (2000). Wealth and stratification processes. Annual Review of Sociology, 26(1), 497-524. https://doi.org/10.1146/ annurev.soc.26.1.497

Stöver, B. (2012). The influence of age on consumption. EcoMod2012 3808, EcoMod. Retrieved from http://ecomod.net/system/files/ Discussion\%20Paper_Britta\%20Stoever.pdf

Slesnick, D. (1991). The standard of living in the United States. Review of Income and Wealth. https://doi.org/10.1111/j.1475-4991.1991. tb00379.x

Toivonen, T. (1992). The melting away of class differences? Consumption differences between employee groups in Finland 1955-1985. Social Indicators Research, 26(3), 277-302. https://doi.org/10. 1007/BF00286563

Tomlinson, M. (1994). Do distinct class preferences for foods exist? An analysis of class- based tastes. British Food Journal, 96(7), 11-17. https://doi.org/10.1108/00070709410076315

Twigg, J., \& Majima, S. (2014). Consumption and the constitution of age: Expenditure patterns on clothing, hair and cosmetics among post-war "baby boomers." Journal of Aging Studies, 30, 23-32. https://doi.org/10.1016/j.jaging.2014.03.003

Urbonavičius, S. (2010). Consumers in the face of economic crisis : Evidence from two generations in Lithuania. Ekonomika Ir Vadyba, 15, 827-834.

Uusitalo, L. (1980). Identification of consumption style segments on the basis of household budget allocation. ACR North American
Advances, NA-07. Retrieved from https:///www.acrwebsite.org/ volumes/9715/volumes/v07/NA-07

van Raaij, W. F. (2016). Saving behavior. In W. F. van Raaij (Ed.), Understanding consumer financial behavior: Money management in an age of financial illiteracy. Palgrave Macmillan.

Wittmayer, C., Schulz, S., \& Mittelstaedt, R. (1994). A cross-cultural look at the "supposed to have it" phenomenon: The existence of a standard package based on occupation. ACR North American Advances, NA-21. Retrieved from www.acrwebsite.org/volum es/7632/volumes/v21/NA-21

Yang, Y., Fu, W. J., \& Land, K. C. (2004). A methodological comparison of age-period-cohort models: The intrinsic estimator and conventional generalized linear models. Sociological Methodology, 34(1), 75-110. https://doi.org/10.1111/j.0081-1750.2004. 00148.x

Zaidi, M., \& de Vos, K. (2001). Trends in consumption-based poverty and inequality in the European Union during the 1980s. Journal of Population Economics, 14, 367-390. https://doi.org/10.1007/ s001480000038

Zurawicki, L., \& Braidot, N. (2005). Consumers during crisis: Responses from the middle class in Argentina. Journal of Business Research, 58(8), 1100-1109. https://doi.org/10.1016/j.jbusr es.2004.03.005

Publisher's Note Springer Nature remains neutral with regard to jurisdictional claims in published maps and institutional affiliations. 